\title{
Neurological disorders and therapeutics targeted to surmount the blood-brain barrier
}

\author{
This article was published in the following Dove Press journal: \\ International Journal of Nanomedicine \\ 29 June 2012 \\ Number of times this article has been viewed
}

\author{
Jagat R Kanwar \\ Bhasker Sriramoju \\ Rupinder K Kanwar \\ Nanomedicine Laboratory of \\ Immunology and Molecular Biomedical \\ Research, Centre for Biotechnology \\ and Interdisciplinary Biosciences, \\ Institute for Frontier Materials (IFM), \\ Deakin University, Waurn Ponds, \\ Victoria, Australia
}

\begin{abstract}
We are now in an aging population, so neurological disorders, particularly the neurodegenerative diseases, are becoming more prevalent in society. As per the epidemiological studies, Europe alone suffers $35 \%$ of the burden, indicating an alarming rate of disease progression. Further, treatment for these disorders is a challenging area due to the presence of the tightly regulated blood--brain barrier and its unique ability to protect the brain from xenobiotics. Conventional therapeutics, although effective, remain critically below levels of optimum therapeutic efficacy. Hence, methods to overcome the blood-brain barrier are currently a focus of research. Nanotechnological applications are gaining paramount importance in addressing this question, and yielding some promising results. This review addresses the pathophysiology of the more common neurological disorders and novel drug candidates, along with targeted nanoparticle applications for brain delivery.
\end{abstract}

Keywords: blood-brain barrier, neurological diseases, brain delivery, targeted nanoparticles

\section{Introduction}

Because the population is currently an aging one, neurological disorders, such as neurodegenerative diseases, inflammatory diseases, and brain tumors are becoming more prevalent. ${ }^{1}$ This increasing prevalence has triggered an increase in research focused on developing novel techniques for successful delivery of drugs across the blood-brain barrier. ${ }^{2}$ In general, molecules that penetrate the blood-brain barrier are lipophilic and less than $500 \mathrm{Da}$ in size. ${ }^{3}$ These unique properties limit the number of potential therapeutic tools able to access the brain. ${ }^{2}$ Current research in the area of nanobiotechnology has had an impact on diagnostic tools and drug delivery by developing molecules that are smaller than $100 \mathrm{~nm}$ in size and endowed with special properties. ${ }^{4,5}$ These nanosized particles have an influential role in therapeutics for brain disorders, especially in overcoming and facilitating enhanced treatment options. ${ }^{5,6}$ Hence, it is necessary to understand the physiology of the blood-brain barrier along with the pathology of neurological disorders in order to develop brain-specific therapeutics.

\section{Blood-brain barrier}

The blood-brain barrier is a protective mechanism that controls cerebral homeostasis and provides the central nervous system with unique protection against all foreign matter. $^{7}$ The blood-brain barrier prevents $98 \%$ of small molecules and $100 \%$ of large molecules from reaching the brain. It is located at the level of the capillaries between the blood and cerebral tissue, and is characterized by the presence of tight intracellular junctions and polarized expression of many transport systems..$^{8,9}$ The blood-brain 
barrier is located at the choroid plexus epithelium, which controls the exchange of molecules between the blood and cerebrospinal fluid. ${ }^{8}$

The endothelial cells of the brain differ slightly from other tissues in that they lack fenestrations and are also unique in having tight junctions between them., ${ }^{7,8}$ They express membrane receptors responsible for active transport of nutrients to the brain and excretion of potentially toxic compounds from the cerebral and vascular compartments. Brain endothelium in mammals has highly controlled permeability towards plasmatic compounds and ions, and has high transendothelial electrical resistance. Dysfunction of the blood-brain barrier is seen in many neurological disorders. In the absence of the blood-brain barrier, the brain microvasculature is an extraordinary way to access the brain, with the possibility of distributing molecules to all areas within the brain. The volume occupied by the capillaries and endothelial cells is around $1 \%$ of the total brain volume and, as a result, the brain microvasculature has a total surface area of approximately $20 \mathrm{~m}^{2}$. This highly vascularized network means that every brain cell is located approximately $20 \mathrm{~nm}$ from a capillary. This could allow for rapid diffusion of small molecules delivered to the brain. However, this possibility is limited by the physiological characteristics of the blood-brain barrier. ${ }^{8}$

\section{Neurological disorders}

In Europe alone, $35 \%$ of all the burden of disease come from neurological disorders, and over 1.5 billion people suffer from a pathogenic neurological condition. ${ }^{10}$ Diseases that affect the brain and central nervous system can be divided into a number of categories, including neurodegenerative, neuroinflammatory, and neoplastic diseases.

\section{Neurodegenerative disease Causes of neurodegeneration}

The precise causes and mechanisms of neurodegeneration are unknown as yet. Individuals with a family history of neurodegeneration are at higher risk of neurodegenerative disease, suggesting a role for genes in its initiation. A significant risk factor for developing neurodegeneration is increasing age, ${ }^{11}$ and this has gained special attention because the population aged 65 years and above is increasing in the developed countries. Thus, it can be foreseen that the risk of developing a neurodegenerative disease will increase in the next few years. Abnormalities related to memory and the motor system are seen in the aged, similar to those observed in neurodegeneration. This observation highlights advancing age as a significant risk factor for developing neurodegeneration.
Aging has also been found to be associated with neuronal death in various regions of the brain, followed by shrinkage of the brain. ${ }^{12}$ Further, at autopsy, aged individuals demonstrate the hallmarks of neurodegeneration in the brain, like Lewy bodies in Parkinson's disease and the neurofibrillary tangles seen in Alzheimer's disease. ${ }^{13,14}$ In light of these observations, the question arises as to whether neurodegeneration occurs during the aging process or whether aging itself represents a presymptomatic phase of degeneration? Environmental factors also tend to provoke neurodegeneration, as evident with the observation of the Parkinson's disease-amyotropic lateral sclerosis complex in the Chamorros population after ingestion of a toxic compound obtained from Cycas circinalis. ${ }^{15}$ This is also evident with the toxic compound 1-methyl-4-phenyl-1,2,3,6-tetrahydropyridine (MPTP) which produces parkinsonian symptoms upon ingestion. ${ }^{16}$ The likely mechanisms of neurodegeneration are described as follows, and are summarized in Figure 1.

\section{Excitotoxicity}

Excitotoxicity is mediated via glutamate, the major excitatory amino acid in the central nervous system. Hyperactivity of glutamate receptors may be caused by both endogenous and exogenous stimulation, resulting in deleterious effects on neurons. Excitotoxicity is mediated by repeated stimulation of glutamate receptors, leading to neuronal damage, and possible mechanisms accounting for this could include deregulation of intracellular calcium homeostasis and overproduction of free radicals. ${ }^{17}$

\section{Apoptosis}

Apoptosis, or programmed cell death, has a convincing role in mediating neurodegenerative diseases, particularly Parkinson's disease. Animal models of Parkinson's disease have shown that oxidative stress and mitochondrial dysregulation culminate in activation of the p53-mediated apoptotic cascade, and eventually neuronal death. Neurons that fail to complete this apoptotic phase become necrotic and inflamed which, in turn, leads to neurodegeneration. ${ }^{18}$ The role of nitric oxide in mediating neuronal death cannot be ignored because nitric oxide has a significant role in stimulating inflammation, release of glutamate, and respiratory inhibition. ${ }^{19}$

\section{Neurodegeneration and cell death}

In most of the neurodegenerative diseases, neuropathological changes in the form of neuronal loss are seen, while the remaining neurons tend to show a variety of morphological changes, ranging from normal appearance to a combination 


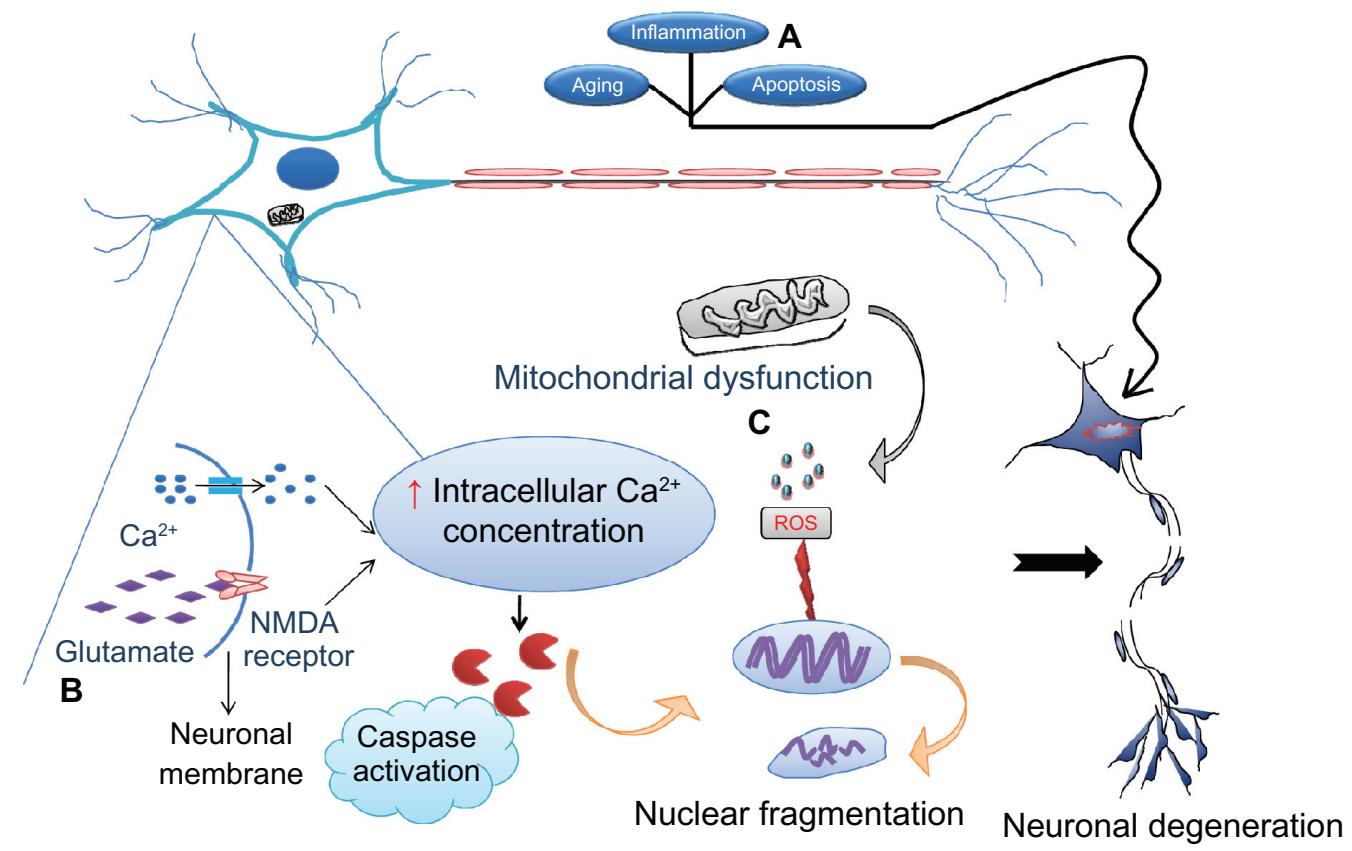

Figure I Various causes of neurodegeneration. Aging and inflammation due to infiltration of T lymphocytes followed by cytokines are the most common risk factors for neurodegeneration. (A) Apoptosis is considered to be programmed cell death that allows clearing out of old cells by inducing their death. However, if the same mechanism becomes dysregulated as a result of mutations, healthy cells also die, leading to neuronal loss followed by symptoms of disease. (B) Excitotoxicity is the other major cause whereby the $\mathrm{N}$-methyl $\mathrm{D}$-aspartate (NMDA) receptor is excessively activated by the endogenous ligand, glutamate. This drives the influx of extracellular calcium intracellularly, activating caspases which in turn destroy the nucleic acids mediating cell death. (C) Mitochondrial dysfunction due to old age or toxins generates free radicals (reactive oxygen species) that defragment DNA.

Note: These processes may occur either independently or collectively under the influence of environmental factors, medications, and infections, precipitate symptoms of neurological disorders.

of changes in size, shape, nuclear defragmentation, and chromatin condensation. Intracellular accumulation of proteins is also evident and useful for differentiating some of the neurodegenerative diseases. For example, intracellular inclusion of Lewy bodies is specific to Parkinson's disease. Earlier, apoptosis and necrosis were considered to be the modes of cell death in neurodegeneration, but the present understanding of neuronal death also includes autophagic and cytoplasmic mechanisms. ${ }^{20} \mathrm{~A}$ brief introduction to the neurodegenerative pathology of Alzheimer's disease and Parkinson's disease is now described.

\section{Alzheimer's disease}

Alzheimer's disease is one of the commonest neurodegenerative diseases, for which only symptomatic therapy is available. Dementia is the primary clinical symptom noticed, along with impaired learning and cognition. As the disease progresses, irritability, confusion, and behavioral changes may persist. ${ }^{5,21,22}$ The brains of patients with Alzheimer's disease show a characteristic pattern of $\beta$-amyloid $(A \beta)$ plaques and neurofibrillary tangles that are considered to be the pathological hallmarks of the disease and progression. $A \beta$ plaques are peptides consisting of 39-42 amino acids and are the result of impaired metabolism of amyloid precursor protein.
Mutations in amyloid precursor protein allow enhanced proteolysis by the $\beta$-amyloid precursor protein-cleaving enzyme ( $\beta$-secretase), followed by increased production of insoluble $\mathrm{A} \beta$ plaques by $\gamma$-secretases. ${ }^{23}$ These $\mathrm{A} \beta$ plaques aggregate readily, remaining a focus for generation of disease and tend to be the real culprits in mediating a variety of destructive effects on neurons, including free radical generation and neuronal loss. ${ }^{24}$ The neurotoxicity is directly associated with toxic $A \beta$-derived oligomers ${ }^{25}$ and diffusible ligands. ${ }^{26}$ Interesting facts have been revealed about the involvement of $A \beta$ plaques in the pathogenesis of Alzheimer's disease, in particular that either an increase in the ratio of $A \beta 42 / A \beta 40$ (insoluble/soluble) plaques or $\mathrm{A} \beta 42$ alone strongly correlates with the predisposition to the disease.

After diagnosis, the amount of $\mathrm{A} \beta$ deposited and its neuroanatomical location reflects the extent of neuronal damage, triggering of tau protein, and dementia. ${ }^{27}$ Other proteins associated with the pathology are neurofibrillary tangles, ie, paired helical filaments of microtubule-associated tau protein. In general, these tangles support the growth of neurons, but become cytotoxic if hyperphosphorylated and disrupt the cytoskeleton. Evidence of neuronal loss, specifically of the cholinergic type, is observed with disease progression, leading to the conclusion that the acetylcholine neurotransmitter 
plays a prominent role in sustaining memory and cognition. ${ }^{24}$ Mutated presenilin 1, presenilin 2, and apolipoprotein E genes have been found to be closely associated with respect to inheritance of the disease. ${ }^{28}$

Current treatments for Alzheimer's disease are mainly the acetylcholine esterase inhibitors, which prevent breakdown of acetylcholine and enhance its bioavailability. The drugs approved are donepezil, rivastigmine, and galantamine. ${ }^{29}$ Memantine falls into the category of N-methyl D-aspartate receptor antagonism, with a proposed mechanism involving inhibition of excitotoxicity. It exhibits this action by antagonizing binding of glutamate (an endogenous excitatory neurotransmitter) to the N-methyl D-aspartate receptor. ${ }^{30}$ Other strategies attempted in the treatment of Alzheimer's disease have included antioxidant and anti-inflammatory drugs, ie, $\alpha$-tocopherol (vitamin E), ${ }^{31}$ ginkgo biloba plant extracts, ${ }^{32}$ and nonsteroidal anti-inflammatory drugs. ${ }^{33}$ The prospects for future therapy are mainly focused on $A \beta$ plaques, aiming either to prevent their formation or solubilize them soon after they have accumulated. Likewise, $\beta$-secretase and $\gamma$-secretase inhibitors would be potentially useful. Another potentially useful strategy has been immunotherapy against $\beta$ amyloid, that has been identified to solubilize the plaques. ${ }^{34}$ Drugs in trials for Alzheimer's disease include semagacestat, a $\gamma$-secretase inhibitor, which acts by inhibiting $A \beta$ plaque formation. ${ }^{35}$

Bapineuzumab $^{36}$ and solanezumab, both humanized monoclonal antibodies, were also tried against $A \beta$ and were effective in solubilizing them. ${ }^{37}$ Intravenous immunoglobulin antibodies against the tau proteins are also effective and undergoing evaluation. ${ }^{38,39}$ Dimebolin hydrochloride, an antihistamine drug with neuroprotective activity, and brainderived neurotrophic factor, which has a substantial influence on neuronal survival, are being evaluated in preclinical studies. ${ }^{40,41}$ Finally, a recent potential target identified is the retinoid $\mathrm{X}$ receptor and its agonist, bexarotene, which has been found to clear A $\beta$ plaques, along with reversal of symptoms, in a murine model of Alzheimer's disease. ${ }^{42}$

\section{Parkinson's disease}

PD is a neurodegenerative disease mostly associated with loss of striatal and dopaminergic neurons in the substantia nigra that coordinate motor movements, along with intracellular inclusions of abnormal proteins called Lewy bodies. ${ }^{43}$ Hence, symptoms commonly found in PD are rigidity, tremors, hypokinesia, and impaired balance. Lewy bodies in the diseased neurons are identified as eosinophilic inclusions, and are considered to be the hallmark of PD and its progression.
Distribution of Lewy bodies is seen in several regions of the brain, accounting for the severe neuronal loss in affected areas. ${ }^{44}$ The etiology of $\mathrm{PD}$ is rather unclear, with a pathology of misfolding and aggregation of proteins, oxidative stress, neuroinflammation, and loss of integrity of the blood-brain barrier. ${ }^{5}$ Mutations are also involved in the disease, and four proteins, ie, $\alpha$-synuclein, ${ }^{45}$ parkin and DJ-1, ${ }^{46}$ and PINK1, ${ }^{47}$ are found to be associated with its inheritance. Upregulation of synuclein mRNA and its protein expression is noticed in lesions of the substantia nigra, that result in induction of neuronal apoptosis.

A possible mechanism correlated with the disease generation is the ability of Lewy bodies to self-aggregate. ${ }^{48,49}$ Mutated versions of parkin and synuclein genes have a major effect on the functioning of the ubiquitin-proteasome system that is responsible for clearing excess, misfolded, or aggregated proteins, leading to accumulation of abnormal proteins and neuronal death. ${ }^{50}$ Finally, free radicals have a significant role in the pathogenesis of neurodegenerative diseases, including PD. ${ }^{51}$ Interesting facts have been revealed about mitochondrial dysfunction and its role in neurodegenerative diseases. The theory is that neurons are always in great demand for mitochondrial energy, and under the influence of aging, environmental factors, or toxins, mitochondrial functioning becomes deregulated and thus the bioenergetic demand for neuronal functioning is unmet. In order to compensate for this, deregulated mitochondria initially stimulate production of $A \beta$ in Alzheimer's disease and synuclein in PD, that ultimately reaches the stage of aggregation, resulting in neuronal death. Localized inflammation is also responsible for deleterious effects in Alzheimer's disease and PD because of increased mitochondrial reactive oxygen species. ${ }^{52}$ This finding opens up a potential new avenue of therapeutic investigation into neurodegenerative diseases. The drugs currently available for PD treat the disease symptomatically, either by mimicking dopaminergic actions or by enhancing the duration of action of dopamine. Drugs mimicking dopamine include the combination of levodopa and carbidopa, with the former acting as a dopaminergic agonist and the latter preventing its metabolism in the periphery. The Duodopa ${ }^{\circledR}$ pump (a prolonged duodenal infusion) is a modified formulation of levodopa and was tried in a patient population that showed significant symptomatic relief. ${ }^{53}$ Other dopaminergic agonists that can be administered include dihydroergocryptine, ropinirole, pramipexole, and pergolide.

Monoamine oxidases are the enzymes responsible for dopamine metabolism, and agents inhibiting these enzymes are found to delay dopamine degradation and thus increase 
its bioavailability. Selegiline is one such drug, and rasagiline is proving to be effective both in vitro and in vivo. ${ }^{54}$ Other modes of treatment that have been tried include stimulation of deeper brain regions and replacement of dysfunctional neurons, but without success. ${ }^{55}$ Future therapies against PD are targeted to oxidative stress, excitotoxicity, and neuronal degeneration. Coenzyme Q10 has been found to have neuroprotective and antioxidant properties, but has not been proven to have a significant clinical effect as yet. ${ }^{56}$ Attempts have been made to evaluate the effects of riluzole, an antiglutamatergic drug, but further clinical evaluation in patients is needed. ${ }^{57}$ Administration of glial-derived neurotrophic factor has shown promising improvement in restoring dopaminergic neurons in animal models of PD. ${ }^{58}$

\section{Stroke}

In terms of neurologic disability, stroke ranks next to Alzheimer's disease and, in general, is the third largest killer next to heart disease and cancer. The statistics for stroke are striking, in that five million deaths are reported each year, and $20 \%$ of men and $25 \%$ of women aged between 45 and 85 years are likely to experience the disease. The prominent risk factors associated with stroke are hypertension, atherosclerosis, diabetes, and heart disease. The main pathology of the disease is vascular occlusion in the brain (ischemic stroke) or vascular rupture (hemorrhagic stroke). ${ }^{59}$ Ischemic stroke is further categorized as thrombotic (localized occlusion of blood vessels), embolic (vessel occlusion due to clot formed elsewhere), or reduced systemic hypoperfusion (due to reduced cardiac function).

However, all of the etiological factors have a common factor, ie, compromised blood supply, that eventually leads to a reduced glucose and oxygen supply to the brain. Because the brain tissue relies completely on aerobic metabolism, and due to the lack of sufficient respiratory reserve, the brain parenchyma suffers death immediately, while the surrounding areas sustain partial damage. Depending on the severity of the ischemic attack, affected brain tissue is designated as the core region, with a severely compromised blood supply, showing necrosis of neurons and glial cells. Areas less severely affected are considered to be the penumbra, and comprise cells that are capable of being revived upon timely therapeutic intervention. ${ }^{60}$ The ischemic cascade sets off a series of events that culminate in neuronal death. In general, neuron survival and transmission of impulses requires a continuous supply of oxygen and glucose, but in the event of ischemic attacks, there is energy depletion that triggers apoptosis, followed by neuronal death.
Ischemia also causes intracellular deregulation of the ions needed for energy exchange. ${ }^{61}$ These destructive events lead to activation of glutamate receptors that cause neuronal damage via abnormal activation of enzymes, generation of free radicals, and excitotoxicity. ${ }^{62}$ The severity of the damage is related to the focus of the origin, duration, and severity of ischemia. Necrosis is predominant in the ischemic core, whereas apoptosis predominates in the surrounding neurons. Ischemic damage initiated by expression of Bcl-2 and p53 is noticed first, followed by release and activation of proapoptotic precursors. ${ }^{63,64}$ Thus, an ischemic attack culminates in irreversible neuronal loss.

Hemorrhagic strokes are defined as ischemic regions containing a variable amount of blood cells leaked from damaged vessels due to either increased vascular wall permeability or post ischemic vessel rupture. Affected brain regions show continuous blood leakage, precipitating hypoxia (due to reduced blood supply), increased intracranial pressure (which in turn negatively affects cerebral blood flow), and persistent irritation. These manifestations are considered to be even more serious than ischemic stroke. One of the subtypes of hemorrhagic stroke identified is intracerebral hemorrhage, which is the result of blood oozing directly from the leaky vessel wall into the brain parenchyma. The potential risk factors identified are hypertension, followed by traumatic brain injuries, angiopathy, blood vessel malformations, and illicit use of medications like amphetamine. Subarachnoid hemorrhage is a less common subtype of stroke, arising from rapid rupture of a basal brain aneurysm. ${ }^{65}$

Therapeutic intervention for stroke is primarily focused on either enhancing the blood supply and/or dissolution of the blood clots formed, by using thrombolytic and neuroprotective strategies. With respect to the thrombolytics available so far, alteplase, or tissue plasminogen activator, is used intravenously in emergencies but has the limitation of severe side effects, including cerebral hemorrhage. ${ }^{66}$ Aspirin, an antiplatelet drug with a possible mechanism of cyclo-oxygenase inhibition, ${ }^{67}$ and lipid-lowering drugs like statins, eg, atorvastatin and lovastatin, which act to prevent formation of cholesterol plaques and their deposition in the walls of blood vessels, are two classes of drugs considered to be of therapeutic benefit for enhancing blood flow. ${ }^{68}$

Monoclonal antibodies have also been tried, and the first one to enter clinical use is abciximab, which acts by inhibiting the glycoprotein IIb/IIIa receptor expressed on the surface of platelets and preventing their aggregation. ${ }^{69}$ The other possible candidate for thrombolysis is heparin, along with fibrinolytic agents like plasmin and microplasmins. 
Although these are beneficial, they are hampered by the same side effects seen with tissue plasminogen activator. ${ }^{70}$ Angiotensin-converting enzyme inhibitors, eg, enalapril and ramipril, and angiotensin II receptor blockers, eg, losartan and valsartan, regulate altered blood pressure by acting on the renin-angiotensin-aldosterone system. Angiotensin II receptor blockers also have anti-inflammatory effects that are suitable for use in the management of stroke. ${ }^{71}$ A novel drug investigated for stroke is edaravone, a free radical scavenger with potential neuroprotective ability, which is used in combination with tissue plasminogen activator for effectiveness. ${ }^{72}$ The following drugs with neuroprotective activity in stroke have been investigated in trials. Citicoline has been identified as preventing generation of free radicals by inhibiting lipid metabolism and has shown promising preclinical results. ${ }^{73,74}$ Metal ions have a significant potential in mediating the activities of enzymes. Hence, the DP-b99 metal chelator (chelates zinc, calcium, iron, and copper ions) was investigated preclinically and clinically in Phase II studies, and reduced areas of ischemic infarct were observed. ${ }^{75,76}$ Finally, valproic acid, sodium butyrate, and trichostatin-A, all histone deacetylase inhibitors with potential anti-inflammatory and antiapoptotic activity, have undergone preclinical investigation. These agents were effective in reducing infarct size and are now heading towards clinical trials. ${ }^{77}$ A recent update in stroke research is ReN001, ie, neural stem cell therapy, which is undergoing evaluation in a small patient group. ${ }^{78}$

\section{Neuroinflammation}

According to the published data, neuroinflammation has a significant role in mediating several neurological disorders, and constant vigilance by immune cells is necessary for neuronal defense, repair, and homeostasis. Pioneering research by Moalem et al ${ }^{79}$ showed that self-reactive $\mathrm{T}$ cells and activated macrophages promote neuronal survival and growth. However, the limitation of exploiting inflammatory processes in the brain is that, unlike epidermal cells in the periphery, neurons cannot be sacrificed because of their limited potential for regeneration. Neuroinflammatory processes are mediated principally by the key players of the brain's innate immune system, ie, microglial cells, that are only equipped with dedicated antigen-presenting potential, and have been found to be involved in several central nervous system disorders, including Alzheimer's disease, multiple sclerosis, and infections, which substantiates their pathological role. The term neuroinflammation is denoted by the response of the inflammatory glial cell (particularly the microglia) that is specific to the central nervous system and characterized by formation of lesions, neurite growth disorders, and hyperphosphorylation of tau proteins, which are completely different to the inflammatory events taking place in the periphery. This understanding has led to the hypothesis that the microglia are the primary immune cells in the brain and respond in a unique way to an inflammatory insult by stimulating cytokines and characteristic phagocytic mechanisms. ${ }^{80}$ In order to understand neuroinflammation better, the terms "acute inflammation" and "chronic inflammation" have been introduced.

Acute inflammation is basically a protective mechanism enabling recovery from an insult and is seen as an immediate response to the causative agent, lasting only for a short time period. Soon after the insult, activated microglia and astrocytes aggressively stimulate targeted cell activation that is similar to the events seen in the periphery. However, there is no evidence of leukocyte infiltration in the brain unless the blood-brain barrier is severely damaged; but if the leukocyte permeation is seen, severe destruction results. ${ }^{81,82}$ In contrast, chronic inflammation indicates a disease state because the inflammation persists for a longer duration of time. Multiple sclerosis is a classical example of chronic inflammation, the details of which are described as follows.

\section{Multiple sclerosis}

Multiple sclerosis is a chronic demyelinating inflammatory central nervous system disease characterized by immune attack directed towards myelin, the protective neuronal sheath. ${ }^{83}$ It affects more than one million people globally, and patients present with symptoms of weakness, ataxia, fatigue, sensory and vision loss, and impaired memory. The severity of these symptoms is determined by the amount of demyelination present, and the more severe the damage, the less the neurons can communicate with each other. ${ }^{22}$ The exact etiology of the disease remains elusive, but it is fascinating to study the infiltration of autoreactive immune cells followed by generation of inflammatory lesions.

\section{T cell infiltration in multiple sclerosis}

A group of self-reactive $\mathrm{T}$ cells directed against myelin crosses the blood-brain barrier under a strong chemokine influence. ${ }^{84}$ The autoreactive T cells gain entry to the central nervous system after binding of their cell surface molecules, ie, P-selectin glycoprotein ligand-1, very late antigen-4, and leukocyte function-associated antigen-1, with the corresponding cell adhesion molecules, ie, mucosal addressin cell adhesion molecule (MAdCAM), vascular cell adhesion molecule, and intracellular cell adhesion molecule, expressed 
on endothelial cells of the brain capillary walls. Soon after their entry, T cells unleash an immune attack on myelin, which becomes sustained by involvement of microglial cells, macrophages, dendrites, and astrocytes, which attract immune cell trafficking. ${ }^{85,169}$ In particular, a specific subset of T helper cells (Th-17) has been identified to be the leading cause of multiple sclerosis, because they secrete interleukin-17 and are endowed with an ability to open the blood-brain barrier, thereby driving the neuronal insult. ${ }^{86}$ In addition, the immune attack towards myelin is boosted by recruitment of $T$ cells from the periphery and activation of antibody-secreting B cells by reactive $T$ cells, culminating in an assault on myelin, followed by demyelination. ${ }^{87,88}$ Based on severity of symptoms, multiple sclerosis is classified into four subtypes. The first subtype is relapsing-remitting multiple sclerosis, whereby patients show recovery following periods of disability. The second form is secondary progressive multiple sclerosis, whereby symptoms of disability are seen between periods of relapse and recovery. The third subtype is primary progressive multiple sclerosis, which, as its name suggests, involves only symptoms of disease progression without any remission. The last subtype is progressive relapsing multiple sclerosis, which is rather rare, with unique symptoms of disease exacerbation during periods of remission. ${ }^{89}$

The advent of biomarkers has paved the way for better understanding of the pathology of multiple sclerosis. These biomarkers include the cytoskeletal proteins of astrocytes and axons, ie, glial fibrillary acidic protein and neurofilament light protein, which are found to be increased in the cerebrospinal fluid of patients with neurological disability and disease progression. ${ }^{90}$ A longitudinal cross-sectional study conducted by Hennies et $\mathrm{al}^{91}$ reported elevated levels of pentosidine, a biomarker of advanced glycation end products, in patients with multiple sclerosis when compared with healthy volunteers. The same was also confirmed by the finding of downregulation of pentosidine upon treatment, substantiating the therapeutic potential of advanced glycation end products as inhibitors in the future.

\section{Multiple sclerosis and its treatment}

Therapeutic interventions for multiple sclerosis mainly target immune suppression to slow disease progression and ameliorate its symptoms. First-line drugs currently used for relapsing-remitting multiple sclerosis are the interferon (IFN) agents, ie, IFN-1, IFNb1a, and IFNb1b, along with glatiramer acetate. The precise mechanism by which these drugs act involves downregulation of T cell proliferation and migration, reduction in antigen presentation, and even shifting the immune response to Th2 cells. ${ }^{92,93}$ Corticosteroids also exert negative effects on the immune system, and are commonly used in the treatment of relapsing-remitting multiple sclerosis. These include prednisone, prednisolone, methylprednisolone, and dexamethasone; however, these drugs have limited application in the treatment of other forms of multiple sclerosis because they are associated with many side effects. ${ }^{94}$ Chemotherapeutics targeting the mechanism of immune suppression have also been attempted. For instance, mitoxantrone and cyclophosphamide have been found to be effective against relapsing-remitting multiple sclerosis and secondary progressive multiple sclerosis, with the former inducing apoptosis of lymphocytes and the latter showing activity against both $\mathrm{T}$ and $\mathrm{B}$ cells..$^{95,96}$

Strenuous efforts are being made to identify better therapeutics for multiple sclerosis, and drugs entering preclinical and clinical trials are gaining momentum. Several drug candidates are being tried preclinically, of which methylthioadenosine has been particularly promising in experimental autoimmune encephalomyelitis, an in vivo model of multiple sclerosis. This molecule, derived from a natural source, shows characteristic immunomodulatory activity and synergistic efficacy when given in combination with IFN or glatiramer acetate. ${ }^{97}$ Recently, it was found that a cytokine known as midkine, upon binding with heparin, triggered an inflammatory cascade attracting $\mathrm{T}$ cell traffic. Animal studies have found that midkine inhibitors are potent enough to reverse experimental autoimmune encephalomyelitis. ${ }^{98}$ Sodium phenylbutyrate, a histone deacetylase inhibitor, has also been shown to ameliorate symptoms of multiple sclerosis in an experimental autoimmune encephalomyelitis model. ${ }^{99}$ A possible mechanism by which the histone deacetylase inhibitors exert a therapeutic effect is inhibition of inflammation and promotion of neuroprotection. ${ }^{100}$ Recent reports by Zhao et al concluded that matrine, a quinolizidine alkaloid obtained from radix Sophorae flavescentis, reduces infiltration of lymphocytes into the central nervous system, thereby ameliorating experimental autoimmune encephalomyelitis. ${ }^{101}$ Drugs included in the Phase II clinical trials were fingolimod and BG00012. The former was found to prevent entry and trafficking of lymphocytes in the central nervous system by encouraging complexation of lymphocytes within the lymph nodes, while the latter showed neuroprotective antiinflammatory activity when administered orally. ${ }^{102}$ Drugs that have reached Phase III investigation include laquinimod, which shifts the cellular immune response to a Th2 type, and teriflunomide, which inhibits the pyrimidine synthesis essential for immune cell proliferation and expansion. 
Cladribine is another candidate drug which is effective against multiple sclerosis, with the proposed mechanism being inhibition of the adenosine deaminase enzyme followed by suppression of dividing and resting T cells. ${ }^{103,104}$ Dalfampridine was recently approved by the US Food and Drug Administration and produces symptomatic improvement of ambulation in patients with multiple sclerosis. The probable mechanism by which this drug acts is via blockade of potassium channels and improving axonal conduction. ${ }^{105}$ Promising results were also seen after introduction of monoclonal antibodies that downregulate the immune response. One is alemtuzumab, which specifically targets CD52 expression, lowers lymphocyte, monocyte, and dendritic cell counts, ${ }^{106}$ and another is rituximab, which has unique activity against $\mathrm{CD} 20$, reducing the $\mathrm{B}$ cell population in cerebrospinal fluid of patients with multiple sclerosis. ${ }^{107}$

Natalizumab, a humanized monoclonal antibody, was found to be effective in patients with relapsing-remitting multiple sclerosis by inhibiting $\alpha$-integrin, a cell surface molecule, and blocking permeation of $\mathrm{T}$ cells into the central nervous system. ${ }^{108}$ Stem cell transplantation was also attempted in a group of patients with multiple sclerosis, with encouraging results. This strategy now warrants further evaluation. ${ }^{109}$

\section{Neuro oncology}

Neuro oncology refers to a wide range of brain tumors growing inside the central nervous system. There is a multitude of neoplasms that originate in the brain, arising either from neural elements or resulting from metastasis of primary tumors situated elsewhere in the body. A variety of malignant brain tumors exist, including gliomas, medulloblastomas, and primary central nervous system lymphomas, as well as tumors that have metastasized to the brain. ${ }^{110}$ Age and gender seem to be associated with certain types of central nervous system malignancy. For instance, malignant astrocytoma and glioblastoma multiforme are the most commonly identified primary brain tumors in male adults, whereas astrocytoma, medulloblastoma, and glioblastoma are predominantly found in children. Risk factors associated with brain tumors include a genetic predisposition to inherited abnormalities, adenomatous polyps, tuberous sclerosis, ionizing radiation, radiofrequency signals emitted from mobile phones, retroviral infection, adenoviruses and papovaviruses, carcinogenic chemicals (alkylating agents), and traumatic head injury. ${ }^{111}$ Gliomas are the commonest form of aggressive brain malignancy, accounting for more than $60 \%$ of primary tumors in the central nervous system, and are further classified as astrocytoma, oligodendroglioma, ependymoma, and glioblastoma multiforme. Based on the extent of cancerous growth, they are considered as low-grade or high-grade gliomas, with the survival rate decreasing upon detection of high-grade glioma. Astrocytomas are considered to be relatively benign, but often undergo mutation, advancing to high-grade astrocytoma or glioblastoma multiforme. Oligodendrogliomas are low-grade tumors, seen usually in middle-aged individuals with a history of seizures. These tumors can be diagnosed very accurately and are best treated by surgical excision. Ependymomas typically arise from cells covering the ventricles and may produce hydrocephalus. The most aggressive and malignant form of astrocytoma is considered to be glioblastoma multiforme. It has the typical characteristics of malignancy, with aggressive growth, invasion, and metastasis. ${ }^{112}$ Gold standard therapy for high-grade gliomas is a combination of surgery and external beam radiation. However, use of chemotherapeutics is also encouraging in these patients. Alkylating agents (procarbazine, temozolomide, carboplatin), nitrosoureas (lomustine, carmustine), vincristine, and topoisomerase inhibitors, eg, irinotecan, are the most promising cytotoxic agents that have been used so far to treat glioma. The mechanisms of these drugs include DNA alkylation, cell cycle phasespecific inhibition, and DNA strand fragmentation.

Cytostatic agents are now gaining popularity, and drugs like tamoxifen which inhibit protein kinase $\mathrm{C}$ have shown promising effects. Retinoic acid, with its ability to induce differentiation followed by apoptosis, and thalidomide, which decreases angiogenesis, are the other drugs included in this category. ${ }^{113}$ Primary central nervous system lymphoma is reasonably infrequent but aggressive, and constitutes $4 \%$ of all primary brain tumors. It takes the form of B cell lymphoma and is confined to the brain and/or spinal cord regions, without systemic lymphocytic involvement. ${ }^{114}$ Whole brain radiation therapy was initially the standard treatment for primary central nervous system lymphoma, but this has become used less frequently with the advent of effective chemotherapeutics. The maximum therapeutic outcome was observed for a combination of chemotherapy with cranial irradiation. A Phase II clinical trial has demonstrated the best patient response using a regimen of methotrexate, procarbazine, and vincristine given intravenously in combination with intrathecal methotrexate followed by whole brain radiation therapy. ${ }^{115,116}$ 
Medulloblastoma is a common brain malignancy in the pediatric population but accounts for only about $1 \%$ of all brain tumors in adults, so there is a need to optimize the therapeutic regimen as per the pediatric setting. ${ }^{114}$ First-line therapy for medulloblastoma is surgical excision of the tumor bed followed by cranial irradiation. Chemotherapy in combination with radiotherapy is worthy of consideration for patients with unresponsive disease. The chemotherapeutic regimen includes cyclophosphamide, lomustine, cisplatin, carboplatin, vincristine, and etoposide. ${ }^{117,118}$ Tumors metastasizing to the brain are the most commonly diagnosed brain tumors. Autopsy studies have indicated that approximately $25 \%$ of patients diagnosed with systemic cancers have metastases to the brain. ${ }^{119}$

Although chemotherapeutics are effective, the side effects are significant, so the present research is focused on small molecule inhibitors targeting the intracellular kinases, farnesyl transferases and matrix metalloproteinases. Protein kinases are of particular importance because they regulate cell proliferation and are overexpressed in malignant cells.

Intracellular signaling pathways are mainly regulated by phosphorylation via protein kinases, and several protein kinase inhibitors, including ZD1839 (gefitinib), OSI774 (erlotinib), and STI-571(imatinib), are undergoing clinical evaluation. Farnesyl transferases are the enzymes responsible for farnesylation of Ras proteins, which are essential for cellular proliferation, survival, and angiogenesis. Hence, by blocking the farnesyl transferase enzyme, farnesyl transferase inhibitors inhibit the farnesylation essential for proliferation of cancer cells. R115777 is another drug included in this category. ${ }^{120}$ Another attractive target is the matrix metalloproteinases, which are overexpressed in glioma, allowing tumor cell invasion and metastatic spread. This is because of the role of matrix metalloproteinases in digestion of the cellular basement membrane and breakdown of the extracellular matrix. Hence, drugs like marimastat and prinomastat that inhibit matrix metalloproteinases are being considered for therapeutic screening. ${ }^{121}$

\section{Blood-brain barrier and neurological disorders: therapeutic options}

The blood-brain barrier is a complex network of vasculature comprised of a tight layer of capillary endothelial cells along with clusters of enzymes, efflux pumps, receptors, and transporters acting in concert to limit access of molecules to the central nervous system. However, if the molecules are permeabilized, they become distributed throughout the brain as a result of its rich vasculature. ${ }^{122}$ As stated earlier, the major limitation in the treatment of neurological disease is the inability to deliver drug molecules across the blood-brain barrier. Therefore, the main focus of research is the development of treatment strategies targeting specific markers on the capillary endothelium associated with the various pathologies. The targeting agents could be antibodies or substrates for receptors, or could be drug-loaded nanoparticles. ${ }^{123,124}$

Conjugating drug molecules to brain-specific transporters will enhance their penetration into the central nervous system. These include transporters of glucose, oligonucleotides, amino acids, and monocarboxylic acid, for which the receptormediated transport system has been the most extensively studied. The transferrin receptor, for example, is found to be more selectively expressed on the capillary endothelium in the brain than in the rest of the body, so represents a potential transport system to deliver drug molecules to the brain. ${ }^{125,126}$ In terms of delivery of therapeutics, enhancing lipophilicity by chemical means would increase drug distribution in the central nervous system. Utilizing biology-based approaches, eg, designed carriers resembling the in situ milieu would also increase penetration of drug molecules into the brain. These tailor-made carriers can be either drugs alone or polymeric nanocarriers modified with the special ability of recognition. Customizing drugs to resemble the in vivo substrates of a normal transporter would also facilitate transport across the blood-brain barrier. However, the real challenge lies in drug modifications which have the probability of losing functionality. ${ }^{122} \mathrm{~A}$ list of conventional and novel therapeutic interventions is shown in Table 1.

\section{Why nanotechnology?}

Nanoparticles are typically characterized as colloidal drug delivery systems with a size measuring not more than $100 \mathrm{~nm}$, and have significant potential for delivering drugs across the blood-brain barrier. The main reason behind the introduction of nanoparticles into the medical field is that they have characteristic features not possessed by conventional therapeutic agents. Because of their small size, nanoparticles tend to have a large surface to volume ratio, providing a huge surface area that favors absorption. This large surface area also imparts the unique ability to absorb/bind a variety of substances, such as therapeutic and diagnostic agents. The unusually small size of the nanoparticle allows easy cellular permeation and evasion of the 
Table I Conventional and future therapeutics for neurological disorders

\begin{tabular}{|c|c|c|c|c|}
\hline S no & Drug molecule & Mechanism & Effective against & Reference \\
\hline I & Donepezil, rivastigmine, and galantamine & Acetylcholinesterase inhibition & $A D$ & 29 \\
\hline 2 & Memantine & $\mathrm{N}$-methyl D-aspartate receptor antagonism & $A D$ & 30 \\
\hline 3 & $\alpha$-tocopherol, ginkgo biloba plant extracts & Antioxidant and anti-inflammatory & $A D$ & 32 \\
\hline 4 & $\begin{array}{l}\text { L-dopa and carbidopa, Duodopa } \\
\text { pump, dihydroergocryptine, ropinirole, } \\
\text { pramipexole, and pergolide }\end{array}$ & Dopaminergic agonism & PD & 53 \\
\hline 5 & Selegiline and rasagiline & Monoamine oxidase inhibition & PD & 54 \\
\hline 6 & Alteplase & Tissue plasminogen activation & Stroke & 66 \\
\hline 7 & Aspirin & COX inhibition & Stroke & 67 \\
\hline 8 & Statins & Cholesterol synthesis & Stroke & 68 \\
\hline 9 & Heparin, plasmin, and micoplasmin & Thrombolysis and fibrinolysis, respectively & Stroke & 70 \\
\hline 10 & Edaravone & Anti-oxidant and neuroprotection & Stroke & 72 \\
\hline 11 & IFN-I, IFNbIa, and IFNbIb & Immune modulation & MS & 92 \\
\hline 12 & Glatiramer acetate & Immune modulation & & 93 \\
\hline 13 & Corticosteroids & Immune suppression & & 94 \\
\hline 14 & Mitoxantrone & Lymphocyte apoptosis & & 95 \\
\hline 15 & Cyclophosphamide & Anti- $T$ and anti-B cell activity & & 96 \\
\hline 16 & Dalfampridine & $\mathrm{K}+$ channel blockade & & 105 \\
\hline 17 & Alkylating agents and nitrosoureas & DNA alkylation followed by apoptosis & Gliomas and & 113 \\
\hline 18 & Vincristine & Cell cycle phase-specific inhibition & medulloblastoma & 117 \\
\hline 19 & Topoisomerase inhibitors & DNA strand fragmentation & & \\
\hline 20 & Whole brain radiation therapy & & $\begin{array}{l}\text { Primary central nervous } \\
\text { system lymphoma }\end{array}$ & 114 \\
\hline \multicolumn{5}{|c|}{ Drugs in preclinical studies } \\
\hline I & Immunotherapy against $\beta$ amyloid & Plaque dissolution & $A D$ & 34 \\
\hline 2 & Brain-derived neurotrophic factor & Neuronal survival and development & $A D$ & 41 \\
\hline 3 & Bexarotene & Dissolution of $A \beta$ plaques & $A D$ & 42 \\
\hline 4 & Glial-derived neurotrophic factor & Dopaminergic neuron revival & $\mathrm{PD}$ & 58 \\
\hline 5 & Citicoline & Lipid metabolism inhibition & Stroke & 73 \\
\hline 6 & DP-b99 & Metal chelation & Stroke & 75 \\
\hline 7 & $\begin{array}{l}\text { Valproic acid, sodium } \\
\text { butyrate, and trichostatin A }\end{array}$ & Anti-inflammatory and antiapoptotic activity & Stroke & 77 \\
\hline 8 & Methylthioadenosine & Immunomodulatory action & MS & 97 \\
\hline 9 & Midkine inhibitors & Anti-inflammatory action & MS & 98 \\
\hline 10 & Histone deacetylase inhibitors & Anti-inflammatory and neuroprotective activities & MS & 100 \\
\hline 11 & Matrine & Reduced lymphocyte infiltration & MS & 101 \\
\hline \multicolumn{5}{|c|}{ Drugs in clinical trials } \\
\hline I & Semagacestat & $\gamma$-secretase inhibitor & $A D$ & 35 \\
\hline 2 & Intravenous immunoglobulin & Passive immunization against amyloid & $A D$ & 38 \\
\hline 3 & Dimebon & Neuroprotection & $A D$ & 40 \\
\hline 4 & Riluzole & Antiglutamatergic drug & PD & 57 \\
\hline 5 & ReNOOI & Neural stem cell therapy & Stroke & 78 \\
\hline 6 & $\begin{array}{l}\text { Fingolimod and } \\
\text { BG000I2 (phase II) }\end{array}$ & $\begin{array}{l}\text { Lymphocyte complexation and neuroprotective } \\
\text { and anti-inflammatory }\end{array}$ & MS & 102 \\
\hline 7 & Laquinimod (phase III) & Shifting the $T$ cell response to $T$ helper 2 type & MS & 103 \\
\hline 8 & Teriflunomide (phase III) & Interrupting pyrimidine synthesis & MS & \\
\hline 9 & Cladribine & Acts against resting and dividing $\mathrm{T}$-cells & MS & \\
\hline 10 & $\begin{array}{l}\text { ZDI839 (gefitinib), OSI774 (erlotinib), } \\
\text { and STI-57I (imatinib) }\end{array}$ & Protein kinase inhibition & Glioblastoma & 120 \\
\hline 11 & RII5777 & Farnesyl transferase inhibition & & \\
\hline 12 & Marimastat and prinomastat & Matrix metalloproteinase inhibiton & Brain tumors & 121 \\
\hline \multicolumn{5}{|c|}{ Monoclonal antibodies } \\
\hline I & Bapineuzumab, solanezumab & Plaque dissolution & $A D$ & 37 \\
\hline 2 & Abciximab & Glycoprotein Ilb/Illa antagonism & Stroke & 69 \\
\hline 3 & Natalizumab & Inhibits entry of T cells & MS & 108 \\
\hline 4 & Alemtuzumab & Depletion of lymphocytes & MS & 106 \\
\hline 5 & Rituximab & Depletion of lymphocytes & MS & 107 \\
\hline
\end{tabular}

Abbreviations: AD, Alzheimer's disease; COX, cyclo-oxygenase; IFN, interferon; MS, multiple sclerosis; PD, Parkinson's disease; S no, serial number. 
reticuloendothelial system, so avoiding unnecessary drug loss. To summarize:

- Nanoparticles deliver therapeutics to the desired site, overcoming the limitations of membrane barriers that are considered impermeable to conventional drug delivery systems.

- Surface-modified nanoparticles are advantageous in terms of site-specific delivery, reducing peripheral toxicity and enabling controlled drug release kinetics.

- Stability of the drug molecule is retained, and after reaching the desired site, drug release is attained by diffusion or erosion from the polymeric nanoparticle wall. ${ }^{127-129}$

The advent of nanotechnology has revolutionized therapeutic delivery, and enabled the manufacture of tailor-made materials that can interact with targets selectively and achieve the desired physiological response.

\section{Why targeted nanodelivery?}

Ideally, for successful treatment, the drug molecule encapsulated in a nanoparticle should reach its optimum concentration at the desired site of action, crossing the barriers presented by the body, eg, the blood-brain barrier, and should also retain its therapeutic activity, resisting the extremities while in the circulation. Most importantly, the ideal nanoparticle should be able to act only on abnormal cells, and should spare healthy cells. This can be achieved only if the nanoparticle is aimed at its target selectively and modified accordingly. These two strategies, if applied to a drug-loaded nanoparticle, will have significant potential to improve patient survival without compromising quality of life. Hence, targeted nanodelivery systems have gained increasing acceptance in modern therapeutics (Figure 2).

\section{Brain-targeted polymeric nanodelivery}

Although the blood-brain barrier poses a serious limitation for delivery of therapeutics to the brain, this barrier is often surmountable when its integrity is disrupted or when the characteristics of a drug molecule are modified. For instance, administering analogs of bradykinin generates osmotic pressure, thus opening the tight junctions of the blood-brain barrier. This allows paracellular drug transport through the blood-brain barrier. Drug permeation

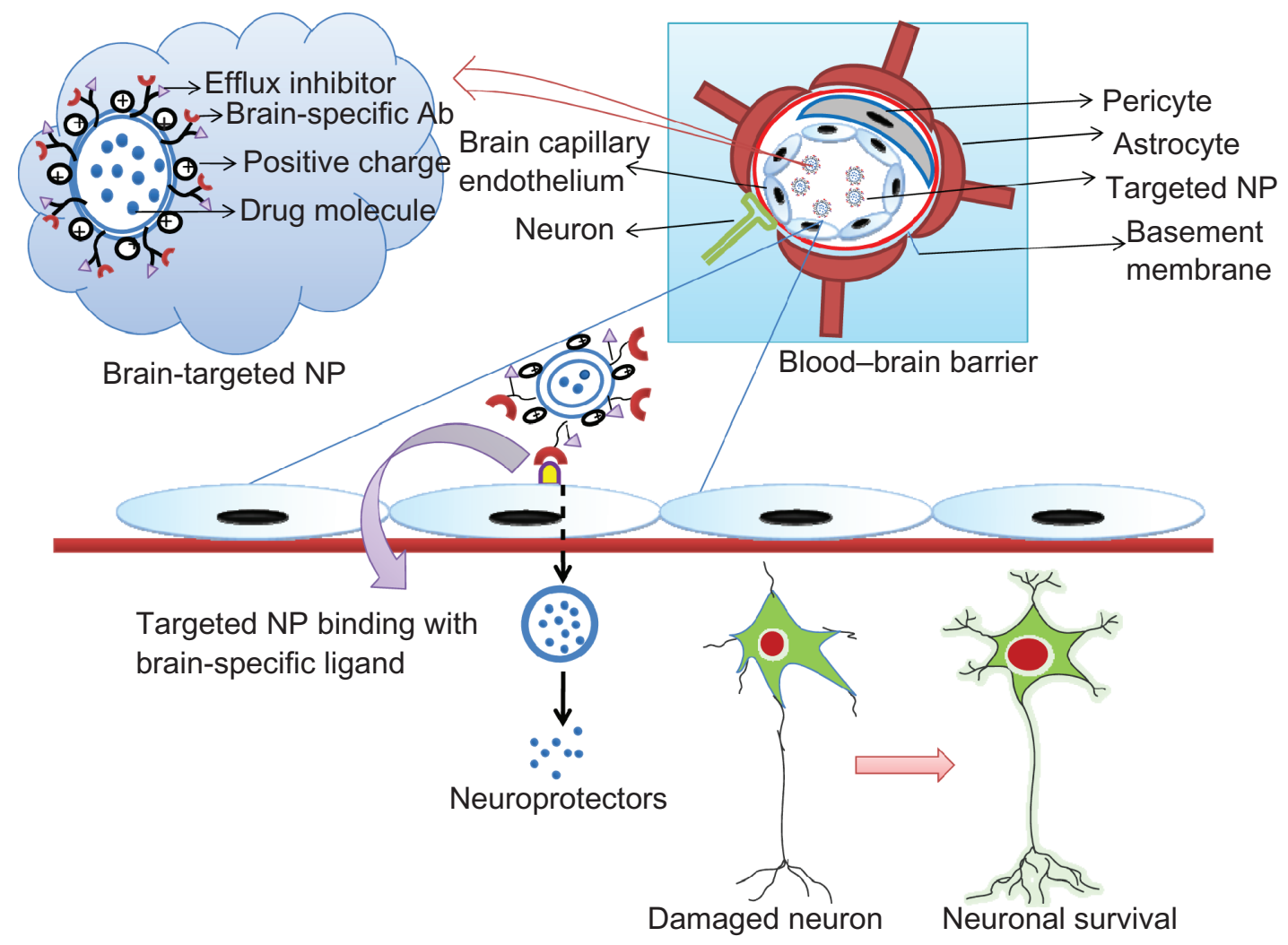

Figure 2 The tightly controlled blood-brain barrier is formed by a triad of brain capillary endothelial cells, pericytes, and astrocytes.

Notes: Surface-modified neuroprotector-loaded nanoparticles bind to brain-specific targets, eg, transferrin, lactoferrin, and low-density lipoprotein receptor-related protein receptors, and permeate into the brain, enhancing their bioavailability. Thus, the neuroprotectors released help to rejuvenate the damaged neurons. Abbreviation: Ab, antibody; NP, nanoparticle. 
has also been reported to be enhanced after intracarotid administration of a hyperosmotic solution of arabinose. ${ }^{130}$ However, these modifications are not always compatible because they disturb homeostasis and allow entry of undesirable toxic molecules along with the therapeutic molecule, leading to potential side effects. Hence, targeted delivery of nanoparticles has become a focus of considerable research attention. The primary objective of a targeted delivery system is to deliver a diagnostic or therapeutic agent to a specific site. Because it is associated with localized delivery, targeted nanoparticles have attracted immense attention over the past 15 years. The potential advantages of site-specific delivery include reduced dosage of the drug molecule, enhanced bioavailability at the desired site, and reduced likelihood of peripheral side effects. Accumulation of nanoparticles at a specific site depends on various factors, and, in general, biodistribution is primarily affected by chemical properties, size of the nanoparticle, and availability of the targeted ligand. Knowledge of the pharmacokinetics of targeted nanoparticles is extremely valuable in evaluating the dose, because although targeted delivery is considered to be site-specific, few nanoparticles seem to distribute to nonspecific sites. ${ }^{131}$

\section{Surface modifications}

\section{Conjugation with antibodies}

Effective targeting requires primarily an understanding of the physiology and anatomy of the blood-brain barrier. One of the approaches is to modify the surface of the drug-loaded nanoparticle by conjugating it with an antibody that is particularly specific for the brain, eg, the OX26 antibody and the transferrin receptor. The antibody-drug conjugate recognizes a specific ligand (the transferrin receptor in this case) and crosses the blood-brain barrier by receptor-mediated endocytosis. Unfortunately, it is hard to identify specific ligands relative to a target tissue. ${ }^{132}$ Antibodies are most promising tools for blood-brain barrier targeting because of their capacity for specific binding. For instance, antibodies targeted to transferrin and insulin receptors can act as transporters across the blood-brain barrier and deposit the drug molecules via receptor-mediated endocytosis. According to the published data, chemotherapeutic drugs like methotrexate and proteins like basic fibroblast growth factor, nerve growth factor, and brain-derived neurotrophic factor, are successfully transported into the brain upon conjugation with the transferrin receptor antibody. ${ }^{133}$ Several other therapeutics, like nerve growth factor and brain-derived neurotrophic factor, are also transported across the blood-brain barrier upon binding with the transferrin receptor antibody. ${ }^{134,135}$ Similarly, megalin ligands patented by Starr et al are specific to the brain and can be used for successful delivery of therapeutics upon surface modification. ${ }^{136}$ Another instance of surface modification being used for delivery of radiopharmaceuticals is [ $\left.{ }^{125} \mathrm{I}\right]-\mathrm{A} \beta^{1-40}$, the uptake of which is significantly increased upon conjugation with a monoclonal antibody against the human insulin receptor following intravenous administration. ${ }^{137}$

A peptide specific to the brain invented by Forni et al can also be suitably modified for conjugating with nanodelivery systems and achieving brain-specific delivery. ${ }^{138}$ A specific method for delivery of this peptide conjugate was developed by Roberts et al, ${ }^{139}$ whereby the peptide intended for delivery was conjugated with a nonpeptide water-soluble polymer. Covalent attachment of the peptide to the polymeric nanoparticle could be achieved if the polymer had a surface modified with water-soluble polyethylene glycol (PEG) or copolymers of PEG and polypropylene glycol.

\section{Surface modification by surfactants}

Interaction of a nanoparticulate system with biological cells is very much influenced by the functionality of the nanoparticle surface. In order to achieve high specificity, the nanoparticle surface can either be modified by conjugating it with an antibody as already discussed, or coating it with different surfactants. ${ }^{140,141}$ Bioadhesive surfactants, such as PEG-D- $\alpha$-tocopheryl, polyethylene glycol 1000 succinate or polyvinyl alcohol can certainly enhance adhesion and adsorption by intestinal cells, while masking efflux mechanisms. However, targeting specificity will primarily depend on the physicochemical and biochemical properties of the surfactant. Previous reports underscore the importance of polysorbate 80 -coated nanoparticles for brain-specific delivery. Polysorbate 80 surface-modified doxorubicin-loaded and gemcitabine-loaded polybutylcyanoacrylate nanoparticles showed enhanced brain specificity and efficacy compared with unmodified nanoparticles, highlighting the importance of surface modification by surfactants. ${ }^{142,143}$ Another surfactant reported to have the ability to enhance brain permeability is poloxamer 188 (F68) which was found to increase the delivery of drug-loaded polybutylcyanoacrylate and poly(lactide-coglycolide) (PLGA) nanoparticles to the brain in rats. ${ }^{144,145}$

A study conducted by Kulkarni et al demonstrated more effective delivery of F68-modified PLGA nanoparticles than F127 and polysorbate 80-modified nanoparticles into the brain. The plausible mechanism behind enhanced brain permeation by these surfactants is that they inhibit the efflux action of P-glycoprotein and solubilize the cell membrane lipids of brain endothelial cells for entry. ${ }^{146}$ Also, polysorbate 80 
and F68 surface-modified nanoparticles adsorb apolipoprotein E, apolipoprotein B, or both, mimic low-density lipoproteins, and enter the brain via receptor-mediated endocytosis. ${ }^{147}$ Thus, it can be understood that surface modification will essentially influence the pattern of nanoparticle uptake by cells.

\section{Applications of targeted delivery in neurological disorders}

Targeted nanoparticle delivery has gained paramount importance for delivery of therapeutics to the brain, and a few of the recent successes are described. The transferrin receptor has gained attention because it favors receptor-mediated endocytosis across the endothelium of brain capillaries. Although expressed in the liver, intestines, and erythroblasts, it is almost undetectable in normal tissues. This approach was used by Gan and Feng, who showed that doxorubicin-loaded poly (lactide)-d- $\alpha$-tocopheryl polyethylene glycol succinate nanoparticles conjugated with the transferrin receptor have enhanced uptake both in vitro and in vivo. ${ }^{148}$ Similar results were obtained with the antioxidant, tempol, loaded into PLGA nanoparticles surface-modified with transferrin, and the investigators suggested that this particular formulation may have applications in Alzheimer's disease and PD. ${ }^{149}$ Substantial results were also obtained upon conjugation of lactoferrin with the surface of the polyamidoamine (PAMAM) dendrimer, with enhanced uptake by the brain capillary endothelium via lactoferrin receptors.

The significance of this study was that lactoferrinconjugated nanoparticles were not in competition with endogenous lactoferrin for binding, corroborating the potential of lactoferrin-mediated surface modification. ${ }^{150}$ Polymeric chitosan nanoparticles modified with an antiamyloid antibody, ie, IgG4.1, were reported to be taken up significantly in an in vitro model of the blood-brain barrier, indicating the future potential of targeted drug delivery for Alzheimer's disease. ${ }^{151}$ Trimethylated chitosan-modified coenzyme-Q10 loaded PLGA nanoparticles were found to have enhanced neuroprotective activity in an in vivo mouse model of Alzheimer's disease, and were internalized via adsorptive-mediated transcytosis. ${ }^{152}$ Similarly, diagnostic improvement was shown by conjugation of the antitau monoclonal antibody to gold nanoparticles. This conjugate showed an extreme sensitivity of detecting $1 \mathrm{pg} / \mathrm{mL}$ of tau protein, thus demonstrating the potential of targeted nanoparticles. ${ }^{153}$ PAMAM dendrimers were modified with Angiopep-2 for selective gene delivery in in vitro and in vivo glioma models. The therapeutic efficiency was reported to be promising, without untoward cytotoxicity and maximum permeation into the brain tumor site. The authors claim that
Angiopep-2 can be suitably ligated to nanoparticles for brainspecific delivery, because they adsorb low-density lipoproteins and undergo receptor-mediated endocytosis, mimicking endogenous lipoproteins. ${ }^{154}$ Similarly chlorotoxin-conjugated DNAloaded PAMAM nanoparticles showed significant uptake in an in vivo glioma model. ${ }^{155}$ A slight modification in ligand binding to PEG-PCL nanoparticles was attempted with Angiopep-2 and EGFP-EGF1. EGFP-EGF1 is a fusion protein derived from coagulation factor VII, and binds specifically to tissue factor, which is overexpressed in neuroglial cells, and this conjugate facilitates enhanced brain penetration and selective accumulation of nanoparticles in these cells. Thus, this strategy, if applied, can be successfully translated for treatment of glioma as well. ${ }^{156}$

Polybutylcyanoacrylate nanoparticles coated with polysorbate 80 have shown enhanced delivery of temozolomide targeting brain tumors in vivo. ${ }^{157}$ An interesting study reported by Guo et al showed enhanced antiglioma therapy using paclitaxel-loaded PEG-PLGA nanoparticles conjugated with DNA aptamer (AS1411) against nucleolin, which is overexpressed in glioma. ${ }^{158}$ Further, conjugation of interleukin-13 peptides with the nanoparticle surface could enhance targeted delivery towards glioma cells, which overexpress the interleukin-13 receptor. ${ }^{159}$ Similarly, PEGPLGA nanoparticles covalently modified with Pep TGN (a 12-amino acid peptide) showed enhanced brain penetration along with reduced accumulation in the liver and spleen in vivo. The significance of this study was that brain-targeted delivery of Pep TGN has never been reported before. ${ }^{160}$ Targeted nanodelivery for neuroinflammation was made possible with the fabrication of PLGA nanoparticles conjugated with leukemia inhibitory factor. Leukemia inhibitory factor was found to have a potential immunoregulatory role, with anti-inflammatory effects driving the maturation of $\mathrm{T}$ regulatory cells and the inhibition of interleukin-6-mediated progression of Th17. This nanoformulation should prove to have substantial application for therapeutics in multiple sclerosis. ${ }^{161}$ Diagnostic applications for multiple sclerosis include glyconanoparticles formulated from cross-linked iron oxide nanoparticles modified with sialyl Lewis X, a ligand specific for selectins. Magnetic resonance imaging has shown increased accumulation of these targeted nanoparticles in an experimental autoimmune encephalomyelitis rat model. ${ }^{162}$ A serious limitation of stroke therapy is systemic hemorrhage due to the nonspecificity of tissue plasminogen activator. Hence, nanodevices have been developed, consisting of tissue plasminogen activator-bound polystyrene latex nanoparticles modified with antifibrin antibody that is selective for clots, thus avoiding nonspecific activity. ${ }^{163}$ 
Simultaneous conjugation of fibrin-specific urokinase (thrombolytic clot buster) and antifibrin antibodies onto perfluorocarbon nanoparticles has shown specific clot dissolution which was found to be effective in an in vivo stroke model. ${ }^{164}$ Table 2 lists the known targeted nanoapplications for neurological disorders.

\section{What's next?}

As already discussed, the strategies needed for brain disorder therapeutics are rather complicated, both in terms of brain penetration and stability of drug molecules following penetration. Hence, applying the principles of neuroprotection or/and neuroproliferation coupled with nanodelivery would be the most reliable technique for resolving some of these challenges. Likewise, we have identified that the mutant form of survivin, SurR9-C84A (baculovirus inhibitor of apoptosis repeat motif) has solid neuroprotective activity when tested in SK-N-SH cells subjected to oxidative stress induced by hydrogen peroxide. ${ }^{165}$ Following this, we also identified the potential of SurR9-C84A in stimulating neuronal proliferation, survival, and expression of neuronal markers when tested in SK-N-SH and HCN-2 cell lines. ${ }^{166}$ Further to this, we also noted the neuroprotective and mitogenic effects of BARF1 epitopes of Epstein-Barr virus. ${ }^{167}$ As already discussed, the impact of neuroinflammation can be drastic because inflammation in itself is toxic to neurons, along with potentiation of neurodegenerative effects. Our previous work has demonstrated promising results in inhibition of inflammation when mice with experimental autoimmune encephalomyelitis were treated with an antiMAdCAM-1 monoclonal antibody that prevented binding and subsequent entry of $\mathrm{T}$ cells.

Surprisingly, neuroprotection was amplified in the experimental autoimmune encephalomyelitis mouse model when the mice were administered a combination of the $\alpha$-amino-3hydroxy-5-methyl-4-isoxazolepropionate/kainate antagonist, 2,3-dihydroxy-6-nitro-7-sulfamoylbenzo(f) quinoxaline, and the neuroprotector, glycine \pm proline \pm glutamic acid (N-terminal tripeptide of insulin-like growth factor). The results included a drastic reduction in disease scores. ${ }^{168}$ Following on from these preliminary achievements, we administered a combination of monoclonal antibodies for MAdCAM-1, vascular

Table 2 Targeted nanotechnological applications

\begin{tabular}{|c|c|c|c|c|c|}
\hline S no & Nanoparticle & Surface modification & Targeted mechanism & Application & Reference \\
\hline $\mathrm{I}$ & PLA-TPGS & Transferrin & Receptor-mediated endocytosis & Enhanced brain uptake & 148 \\
\hline 2 & PLGA & Transferrin & Receptor-mediated endocytosis & $\begin{array}{l}\text { Enhanced brain uptake in } \\
A D \text { and } P D\end{array}$ & 149 \\
\hline 3 & PAMAM & Lactoferrin & Receptor-mediated endocytosis & Gene delivery & 150 \\
\hline 4 & Chitosan & Anti-amyloid antibody, IgG4.I & Binds selectively with amyloid- $\beta$ & Therapeutic for AD & $15 \mid$ \\
\hline 5 & PLGA & Trimethylated chitosan & Absorptive-mediated transcytosis & $\begin{array}{l}\text { Neuroprotector drug } \\
\text { uptake in } A D\end{array}$ & 152 \\
\hline 6 & Gold & Anti-tau monoclonal antibody & Binds selectively with tau proteins & Diagnostic in $A D$ & 153 \\
\hline 7 & PAMAM & Angiopep-2 & LRP-mediated endocytosis & $\begin{array}{l}\text { Enhanced DNA delivery } \\
\text { in glioma }\end{array}$ & 154 \\
\hline 8 & PAMAM & Chlorotoxin & $\begin{array}{l}\text { Binds to matrix } \\
\text { metalloproteinase- } 2 \text { endopeptidase }\end{array}$ & $\begin{array}{l}\text { Enhanced DNA uptake } \\
\text { in glioma }\end{array}$ & 155 \\
\hline 9 & PEG-PCL & Angiopep-2 and EGFP-EGFI & LRP-mediated endocytosis & $\begin{array}{l}\text { Enhanced brain uptake and } \\
\text { selective in glioma }\end{array}$ & 156 \\
\hline 10 & PBCA & Polysorbate- 80 & LRP-mediated endocytosis & $\begin{array}{l}\text { Enhanced temozolomide } \\
\text { brain delivery }\end{array}$ & 157 \\
\hline 11 & PEG-PLGA & DNA aptamer (ASI4II) & Nucleolin binding & $\begin{array}{l}\text { Paclitaxel-selective delivery } \\
\text { in glioma }\end{array}$ & 158 \\
\hline 12 & $\begin{array}{l}\text { Gadolinium } \\
\text { metallofullerenes }\end{array}$ & IL-I 3 peptides & IL-I 3 receptor binding & Selective glioma therapy & 159 \\
\hline 13 & PEG-PLGA & Pep TGN & - & Selective brain penetration & 160 \\
\hline 14 & PLGA & Leukemia inhibitory factor & Immunoregulatory action & $\begin{array}{l}\text { Enhanced activity versus } \\
\text { inflammation in MS }\end{array}$ & 161 \\
\hline 15 & Iron oxide & Sialyl Lewis X & $\begin{array}{l}\text { Binds to selectins expressed in } \\
\text { inflammation }\end{array}$ & Diagnostic in MS & 162 \\
\hline 16 & Polystyrene-latex & Antifibrin $A b$ & Binds to fibrins expressed in clots & Clot-selective in stroke & 163 \\
\hline 17 & Perfluorocarbon & Antifibrin $\mathrm{Ab}$ & Binds to fibrins expressed in clots & Clot-selective in stroke & 164 \\
\hline
\end{tabular}

Abbreviations: Ab, antibody; AD, Alzheimer's disease; IL, interleukin; LRP, low-density lipoprotein receptor-related protein; PAMAM, polyamidoamine; PBCA, polybutylcyanoacrylate; PD, Parkinson's disease; PEG-PCL, polyethylene glycol-polycaprolactone; PEG-PLGA, polyethylene glycol-poly (lactide-co-glycolide); PLA-TPGS, poly(lactide)-D- $\alpha$-tocopheryl polyethylene glycol succinate. 


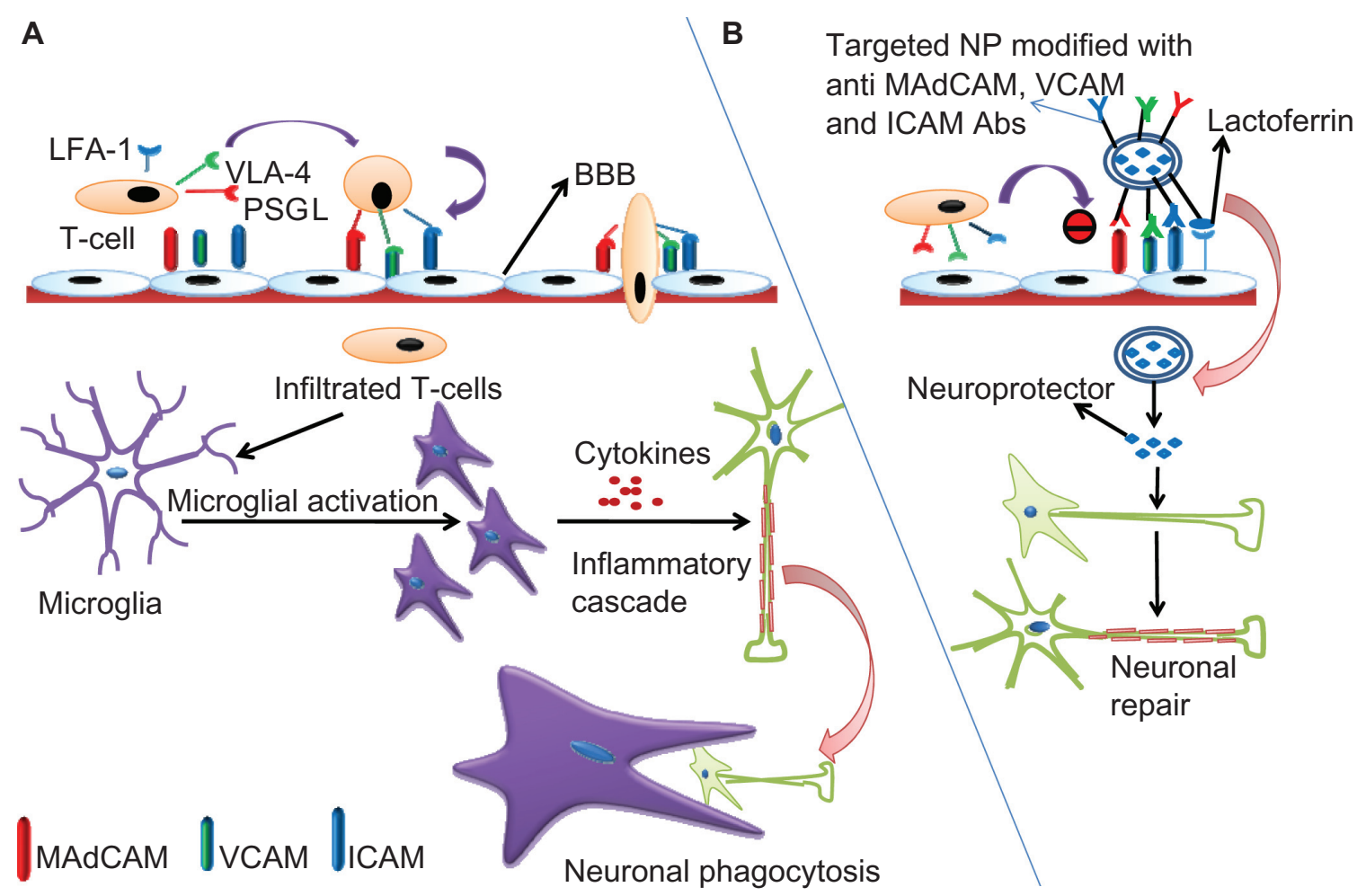

Figure 3 (A) Schematic representation of inflammatory cascade. T cells express cell surface molecules of PSGL-I, VLA-4, and LFA-I that bind with the corresponding cell adhesion molecules, MAdCAM, VCAM, and ICAM expressed on the brain capillary endothelium and permeate into the BBB. Soon after their entry, these surface molecules activate microglial cells which, in turn, secrete cytokines driving more $T$ cell traffic and the inflammatory cascade leading to the neuronal insult. The damaged neurons are then phagocytosed by the microglial cells. (B) Neuroprotector-loaded nanoparticles can be surface-modified by conjugation with lactoferrin and antibodies against MAdCAM, VCAM, and ICAM. Lactoferrin guides specificity for the brain due to abundant availability of low-density lipoprotein receptor-related protein (LRP) while the antibodies inhibit $T$ cell infiltration into the BBB.

Note: Following internalization, the neuroprotector is released from the nanoparticles and initiates the repair mechanisms counteracting inflammation and its consequences. Abbreviations: BBB, blood-brain barrier; PSGL-I, P-selectin glycoprotein ligand-I; VLA-4, very late antigen-4; LFA-I, leukocyte function-associated antigen-I; MAdCAM, mucosal addressin cell adhesion molecule; VCAM, vascular cell adhesion molecule; ICAM, intracellular adhesion molecule; NP, nanoparticle.

cell adhesion molecule-1, intracellular adhesion molecule-1, and leukocyte function-associated antigen-1 molecule, and, not surprisingly, maximum remission of disease symptoms were observed in the mice with experimental autoimmune encephalomyelitis. ${ }^{169}$ Successful results were also achieved by administration of anti-integrin ( $\alpha 4 \beta 7$ and $\alpha E \beta 7)$ antibodies, when integrins were supposed to drive $\mathrm{T}$ cell adhesion in inflammatory conditions. ${ }^{170} \mathrm{We}$ also demonstrated that lactoferrin-conjugated nanoparticles showed enhanced brain uptake via low-density lipoprotein receptor-related proteinmediated endocytosis, confirming selectivity of lactoferrin for the brain (unpublished data). To conclude, the advent of locked nucleic acid delivery could revolutionize gene therapeutics for brain disorders. Locked nucleic acids are a class of modified ribonucleic acids that can potentially improve the stability of DNAs and RNAs, thereby enhancing their bioavailability. ${ }^{171}$ Such agents, that can act as neuroprotectors, neuroproliferators, or both, can be tailor-made when coupled with targeted nanoparticles directing brain-specific delivery and effective therapeutics (Figure 3).

\section{Conclusion}

As the prevalence of the aforementioned neurological diseases increases, so too does the research now developing new therapeutic regimens. In the recent past, targeted delivery of nanoparticles to the brain has gained significant attention, as evidenced with the published data. After thorough investigation, nanotechnological administration has been found to be the most reliable mode of drug administration, given that the challenges of drug delivery to the brain are unmet by conventional therapeutics. Therefore, research into targeted nanoparticle delivery represents a significant area of interest for addressing future research questions.

\section{Acknowledgments}

The authors would like to thank the Australia-India Strategic Research Fund (BF 030016) and Deakin University for their financial support.

\section{Disclosure}

The authors report no conflicts of interest in this work. 


\section{References}

1. Riggs JE. Age specific rates of neurological disease. In: Hof PR, Mobbs CV, editors. Functional Neurobiology of Aging. San Diego, CA Press: Academic Press; 2001.

2. Calvo P, Gouritin B, Villarroya H, et al. Quantification and localisation of PEGylated polycyanoacrylate nanoparticles in brain and spinal cord during allergic encephalomyelitis in the rat. Eur J Neurosci. 2002;15(8):1317-1326.

3. Jain KK. The role of nanobiotechnology in drug discovery. Drug Discov Today. 2005;10(21):1435-1442.

4. Boado RJ. Antisense drug delivery through the blood-brain barrier. Adv Drug Deliv Rev. 1995;15:73-107.

5. Modi G, Pillay V, Choonara YE, Ndesendo VM, Du Toit LC, Naidoo D. Nanotechnological applications for the treatment of neurodegenerative disorders. Prog Neurobiol. 2009;88(4):272-285.

6. Khlebtsov NG, Dykman LA. Optical properties and biomedical applications of plasmonic nanoparticles. J Quantit Spectrosc Radiat Trans. 2009;12:1-35.

7. Roney C, Kulkarni AR, Arora V, et al. Targeted nanoparticle delivery through blood-brain barrier for Alzheimer's disease. J Control Release. 2005;108(2-3):193-214.

8. Weiss N, Miller F, Cazaubon S, Couraud PO. The blood-brain barrier in brain homeostasis and neurological diseases. Biochim Biophys Acta. 2009;1788(4):842-857.

9. Baratchi S, Kanwar RK, Khoshmanesh K, et al. Promises of nanotechnology for drug delivery to brain in neurodegenerative diseases. Curr Nanosci. 2008;5:1-11.

10. Blasi P, Giovagnoli S, Schoubben A, Ricci M, Rossi C. Solid lipid nanoparticles for targeted brain drug delivery. Adv Drug Deliv Rev. 2007;59(6):454-477.

11. Tanner CM. Epidemiology of Parkinson's disease. Neurol Clin. 1992;109(2):317-329.

12. Finch CE, Day JR. Molecular biology of aging in the nervous system: a synopsis of the levels of mechanisms. In: Calne DB, editor. Neurodegenerative Diseases. Philadelphia, PA: Saunders; 1994.

13. Gibb WR, Lees AJ. The significance of the Lewy body in the diagnosis of idiopathic Parkinson's disease. Neuropathol Appl Neurobiol. 1989;15(1):27-44.

14. Anderton BH. Ageing of the brain. Mech Ageing Dev. 2002;123(7): 811-817.

15. Kurtland LT. Amyotrophic lateral sclerosis and Parkinson's disease complex on Guam linked to an environmental neurotoxin. Trends Neurosci. 1988;11(2):51-54.

16. Przedborski S, Vila M. MPTP: a review of its mechanisms of neurotoxicity. Clin Neurosci Res. 2001;1(6):407-418.

17. Relja M. Pathophysiology and classification of neurodegenerative diseases. Available from: http://ifcc.org.instant.cohaesio.net/ifccfiles/ docs/150309200415.pdf. Accessed September 3, 2011.

18. Waldmeier PC. Prospects for antiapoptotic drug therapy of neurodegenerative diseases. Prog Neuropsychopharmacol Biol Psychiatry. 2003;27(2):303-321.

19. Kanwar JR, Kanwar RK, Burrow H, Baratchi S. Recent advances on the roles of NO in cancer and chronic inflammatory disorders. Curr Med Chem. 2009;16(19):2373-2394.

20. Clarke PGH. Developmental cell death: morphological diversity and multiple mechanisms. Anat Embryol. 1990;181(3):195-213.

21. Cui Z, Lockman PR, Atwood CS, et al. Novel D-penicillamine carrying nanoparticles for metal chelation therapy in Alzheimer's disease and other CNS diseases. Eur J Pharm Biopharm. 2005;59(2): 263-272.

22. Nowacek A, Kosloski LM, Gendelman HE. Neurodegenerative disorders and nanoformulated drug development. Nanomedicine (Lond). 2009;4(5):541-555.

23. Scheuner D, Eckman C, Jensen M, et al. Secreted amyloid $\beta$-protein similar to that in the senile plaques of Alzheimer's disease is increased in vivo by the presenilin 1 and 2 and APP mutations linked to familial Alzheimer's disease. Nat Med. 1996;2(8):864-870.
24. Swartz RH, Black SE, St George-Hyslop P. Apolipoprotein E and Alzheimer's disease: A genetic, molecular and neuroimaging review. Can J Neurol Sci. 1999;26(2):77-88.

25. Walsh DM, Klyubin I, Fadeeva JV, et al. Naturally secreted oligomers of amyloid $\beta$ protein potently inhibit hippocampal long-term potentiation in vivo. Nature. 2002;416(6880):535-539.

26. Lambert MP, Barlow AK, Chromy BA, et al. Diffusible, nonfibrillar ligands derived from $A \beta 1-42$ are potent central nervous system neurotoxins. Proc Natl Acad Sci U S A. 1998;95(11): 6448-6453.

27. Karran E, Mercken M, Strooper BD. The amyloid cascade hypothesis for Alzheimer's disease: an appraisal for the development of therapeutics. Nat Rev Drug Discov. 2011;10(9):698-712.

28. Imbimbo BP, Lombard J, Pomara N. Pathophysiology of Alzheimer's disease. Neuroimaging Clin N Am. 2005;15(4):727-753.

29. Lleó A, Greenberg SM, Growdon JH. Current pharmacotherapy for Alzheimer's disease. Annu Rev Med. 2006;57:513-533.

30. Rondi-Reig L, Libbey M, Eichenbaum H, Tonegawa S. CA1specific $N$-methyl-D-aspartate receptor knockout mice are deficient in solving a nonspatial transverse patterning task. Proc Natl Acad Sci U S A. 2001;98(6):3543-3548.

31. Miller ER, Pastor-Barriuso R, Dalal D, Riemersma RA, Appel LJ, Guallar E. Meta-analysis: high-dosage vitamin E supplementation may increase all-cause mortality. Ann Intern Med. 2004;142(1): 37-46.

32. Luo Y, Smith JV, Paramasivam V, Burdick A, Curry KJ, Buford JP. Inhibition of amyloid-beta aggregation and caspase-3 activation by the Ginkgo biloba extract EGb761. Proc Natl Acad Sci U SA. 2002;99(19): 12197-12202.

33. Etminan M, Gill S, Samii A. Effect of non-steroidal anti-inflammatory drugs on risk of Alzheimer's disease: systematic review and metaanalysis of observational studies. BMJ. 2003;327(7407):128.

34. Schenk D, Barbour R, Dunn W, et al. Immunization with amyloid- $\beta$ attenuates Alzheimer-disease-like pathology in the PDAPP mouse. Nature. 1999;400(6740):173-177.

35. Fleisher AS, Raman R, Siemers ER, et al. Phase 2 safety trial targeting amyloid $\beta$ production with a $\gamma$-secretase inhibitor in Alzheimer disease. Arch Neurol. 2008;65(8):1031-1038.

36. Bard F, Cannon C, Barbour R, et al. Peripherally administered antibodies against amyloid $\beta$-peptide enter the central nervous system and reduce pathology in a mouse model of Alzheimer disease. Nat Med. 2000;6(8): 916-919.

37. DeMattos RB, Bales KR, Cummins DJ, et al. Peripheral anti-A $\beta$ antibody alters CNS and plasma $A \beta$ clearance and decreases brain $A \beta$ burden in a mouse model of Alzheimer's disease. Proc Natl Acad Sci US A. 2001;98(15):8850-8855.

38. Fillit H, Hess G, Hill J, Bonner P, Toso C. IV immunoglobulin is associated with a reduced risk of Alzheimer disease and related disorders. Neurology. 2009;73(3):180-185.

39. Oddo S, Billings L, Kessiak JP, Cribbs DH, LaFerla FM. Immunotherapy leads to early, but not late, hyperphosphorylated tau aggregates via the proteasome. Neuron. 2004;43:321-332.

40. Bachurin S, Bukatina E, Lermontova N, et al. Antihistamine agent dimebon as a novel neuroprotector and cognition enhancer. Ann NY Acad Sci. 2001;939:425-435.

41. Nagahara AH, Merrill DA, Coppola G, et al. Neuroprotective effects of brain-derived neurotrophic factor in rodent and primate models of Alzheimer's disease. Nat Med. 2009;15(3): 331-337.

42. Cramer PE, Cirrito JR, Wesson DW, et al. ApoE-directed therapeutics rapidly clear $\beta$-amyloid and reverse deficits in AD mouse models. Science. 2012;335(6075):1503-1506.

43. Michael JZ, Robert EB. Pathophysiology of Parkinson's disease. Neuropsychopharmacology. In: Coyle JT, Charney D, Davis KL, editors. The Fifth Generation of Progress. An Official Publication of the American College of Neuropsychopharmacology. Philidelphia, PA: Lippincott Williams and Wilkins; 1996. 
44. Gibb WR, Scott T, Lees AJ. Neuronal inclusions of Parkinson's disease. Mov Disord. 1991;6(1):2-11.

45. Polymeropoulos MH, Lavedan C, Leroy E, Ide SE, Dehejia A. Mutation in the $\alpha$-synuclein gene identified in families with Parkinson's disease. Science. 1997;276(5321):2045-2047.

46. Van Duijn CM, Dekker MC, Bonifati V, Galjaard RJ, HouwingDuistermaat JJ. Park7, a novel locus for autosomal recessive early-onset parkinsonism, on chromosome 1p36. Am J Hum Genet. 2001;69(3): 629-634.

47. Valente EM, Abou-Sleiman PM, Caputo V, Muqit MM, Harvey K Hereditary early-onset Parkinson's disease caused by mutations in PINK1. Science. 2004;304(5674):1158-1160.

48. Han H, Weinreb PH, Lansbury PTJ. The core Alzheimer's peptide NAC forms amyloid fibrils which seed and are seeded by beta-amyloid: is NAC a common trigger or target in neurodegenerative disease? Chem Biol. 1995;2(3):163-169.

49. Kholodilov NG, Neystat M, Oo TF, et al. Increased expression of rat synuclein 1 in the substantia nigra pars compacta identified by differential display in a model of developmental target injury. J Neurochem. 1999;73(6):2586-2599.

50. Mcnaught KS, Belizaire R, Isacson O, Jenner P, Olanow CW. Altered proteasomal function in sporadic Parkinson's disease. Exp Neurol. 2003;179(1):38-46.

51. Fahn S, Cohen G. The oxidant stress hypothesis in Parkinson's disease: evidence supporting it. Ann Neurol. 1992;32(6):804-812.

52. Coskun P, Wyrembak J, Schriner S, et al. A mitochondrial etiology of Alzheimer and Parkinson disease. Biochim Biophys Acta. 2012;1820(5): 553-564.

53. Karlsborg M, Korbo L, Regeur L, Glad A. Duodopa pump treatment in patients with advanced Parkinson's disease. Dan Med Bull. 2010;57(6): A4155.

54. Pagonabarraga J, Kulisevsky J. Rasagiline: effectiveness and protection in Parkinson's disease. Rev Neurol. 2010;51(9):535-541.

55. Freed CR, Greene PE, Breeze RE, et al. Transplantation of embryonic dopamine neurons for severe Parkinson's disease. $N$ Engl J Med. 2001;344(10):710-719.

56. Shults CW, Haas RH, Beal MF. A possible role of coenzyme Q10 in the etiology and treatment of Parkinson's disease. Biofactors. 1999;9(2-4):267-272.

57. Hunter C, Jankovic J. Double-blind, placebo-controlled study to assess safety and efficacy of riluzole as a neuroprotective drug in patients with early untreated Parkinson's disease. Neurology. 1999;52:214-221.

58. Kordower JH, Palfi S, Chen EY, et al. Clinicopathological findings following intraventricular glial-derived neurotrophic factor treatment in a patient with Parkinson's disease. Ann Neurol. 1999;46(3): 419-434.

59. Ohira T, Shahar E, Chambless LE, Rosamond WD, Mosley TH Jr, Folsom AR. Risk factors for ischemic stroke subtypes: the atherosclerosis risk in communities study. Stroke. 2006;37(10):2493-2498.

60. Turner R, Vink R. Inhibition of neurogenic inflammation as a novel treatment for ischemic stroke. Timely Top Med Cardiovasc Dis. 2007;11:E24.

61. Karaszewski B, Wardlaw JM, Marshall I, et al. Brain temperature elevation and anaerobic metabolism in human acute ischaemic stroke. Brain. 2009;32(Pt 4):955-964.

62. Nakanishi N, Tu S, Shin Y, et al. Neuroprotection by the NR3 A subunit of the NMDA receptor. J Neurosci. 2009;29(16):5260-5265.

63. Joza N, Susin SA, Daugas E, et al. Essential role of the mitochondrial apoptosis-inducing factor in programmed cell death. Nature. 2001; 410(6828):549-554.

64. Ekshyyan O, Aw TY. Apoptosis in neurodegenerative disorders. Curr Neurovasc Res. 2004;1(4):355-371.

65. Augusto DE, Alvarez LM, Costa FT. Update in spontaneous cerebral hemorrhage. Med Intensiva. 2008;32:282-295.

66. Adibhatla RM, Hatcher JF. Tissue plasminogen activator (tPA) and matrix metalloproteinases in the pathogenesis of stroke: therapeutic strategies. CNS Neurol Disord Drug Targets. 2008;7(3):243-253.
67. Weyrich AS, Skalabrin EJ, Kraiss LW. Targeting the inflammatory response in secondary stroke prevention: a role for combining aspirin and extended-release dipyridamole. Am J Ther. 2009;16(2):164-170.

68. Crouse JR, Byington RP, Furberg CD. HMG-CoA reductase inhibitor therapy and stroke risk reduction: an analysis of clinical trials data. Atherosclerosis. 1998;138(1):11-24.

69. Tam SH, Sassoli PM, Jordan RE, Nakada MT. Abciximab (ReoPro, chimeric 7E3 Fab) demonstrates equivalent affinity and functional blockade of glycoprotein IIb/IIIa and avb3 integrins. Circulation. 1998;98(11):1085-1091.

70. Molina CA, Saver JL. Extending reperfusion therapy for acute ischemic stroke. Emerging pharmacological, mechanical and imaging strategies. Stroke. 2005;36(10):2311-2320.

71. Libby P. Current concepts of the pathogenesis of the acute coronary syndromes. Circulation. 2001;104(3):365-372.

72. Abe K. Neuroprotective therapy for ischemic stroke with free radical scavenger and gene-stem cell therapy. Rinsho Shinkeigaku. 2008;48(11):896-898. Japanese.

73. Adibhatla RM, Hatcher JF. Citicoline mechanisms and clinical efficacy in cerebral ischemia. J Neurosci Res. 2002;70(2):133-139.

74. Shuaib A, Yang Y, Li Q. Evaluating the efficacy of citicoline in embolic ischemic stroke in rats: neuroprotective effects when used alone or in combination with urokinase. Exp Neurol. 2000;161(2):733-739.

75. Angel I, Strein S, Schatz G, et al. The lipophilic transition modulator DP-b99 attenuates matrix metalloproteinase activity in a rat MCAO ischaemic model. (Abstract). Soc Neurosci. 2004;100:3.

76. Rosenberg G, Angel I, Kozak A. Clinical pharmacology of DP-b99 in healthy volunteers: first administration to humans. Br J Clin Pharmacol. 2005;60(1):7-16.

77. Kim HJ, Rowe M, Ren M, Hong JS, Chen PS, Chuang DM. Histone deacetylase inhibitors exhibit anti-inflammatory and neuroprotective effects in a rat permanent ischemic model of stroke: multiple mechanisms of action. J Pharmacol Exp Ther. 2007;321(3):892-901.

78. Drugs.com [homepage on the Internet]. ReNeuron gives uptake on stroke clinical trial. [press release]. Available from: http://www.drugs. com/clinical_trials/reneuron-gives-update-stroke-clinical-trial-11261. html. Accessed September 6, 2011.

79. Moalem G, Monsonego A, Shani Y, Cohen IR, Schwartz M. Differential $T$ cell response in central and peripheral nerve injury: connection with immune privilege. FASEB J. 1999;13(10):1207-1217.

80. Streit WJ, Kincaid-Colton CA. The brain's immune system. Sci Am. 1995;273(5):54-61.

81. Sroga JM, Jones TB, Kigerl KA, McGaughy VM, Popovich PG. Rats and mice exhibit distinct inflammatory reactions after spinal cord injury. J Comp Neurol. 2003;462(2):223-240.

82. Streit WJ, Semple-Rowland SL, Hurley SD, Miller RC, Popovich PG, Stokes BT. Cytokine mRNA profiles in contused spinal cord and axotomized facial nucleus suggest a beneficial role for inflammation and gliosis. Exp Neurol. 1998;152(1):74-87.

83. Lucchinetti C, Bruck W, Parisi J, Scheithauer B, Rodriguez M, Lassmann H. Heterogeneity of multiple sclerosis lesions: implications for the pathogenesis of demyelination. Ann Neurol. 2000;47(6): $707-717$.

84. Charo IF, Ransohoff RM. The many roles of chemokines and chemokine receptors in inflammation. $N$ Engl J Med. 2006;354(6):610-621.

85. Heppner FL, Greter M, Marino D, et al. Experimental autoimmune encephalomyelitis repressed by microglial paralysis. Nat Med. 2005; 11(2):146-152.

86. Ontaneda D, Hyland M, Cohen JA. Multiple sclerosis: new insights in pathogenesis and novel therapeutics. Annu Rev Med. 18, 2011; 63:389-404.

87. Cepok S, Rosche, Grummel V, et al. Short-lived plasma blasts are the main B cell effector subset during the course of multiple sclerosis. Brain. 2005;128(Pt 7):1667-1676.

88. Steinman L. A few autoreactive cells in an autoimmune infiltrate control a vast population of nonspecific cells: a tale of smart bombs and the infantry. Proc Natl Acad Sci U S A. 2002;93(6):2253-2256. 
89. Multiple sclerosis. Available from: http://www.mayoclinic.org/ multiple-sclerosis. Accessed September 5, 2011.

90. Axelsson M, Malmeström C, Nilsson S, Haghighi S, Rosengren L, Lycke J. Glial fibrillary acidic protein: a potential biomarker for progression in multiple sclerosis. J Neurol. 2011;258(5):882-888.

91. Hennies C, Sternberg D, Bistulfi GL, et al. Plasma pentosidine: a potential biomarker in the management of multiple sclerosis. Mult Scler. 2011;17(2):157-163.

92. Clerico M, Contessa G, Durelli L. Interferon-beta1a for the treatment of multiple sclerosis. Expert Opin Biol Ther. 2007;7(4):535-542.

93. Arnon R, Aharoni R. Mechanism of action of glatiramer acetate in multiple sclerosis and its potential for the development of new applications. Proc Natl Acad Sci U S A. 2004;101 Suppl 2:14593-14598.

94. The Merck Manual Home Health Handbook. Multiple sclerosis. Available from: http://www.merckmanuals.com/home/brain_spinal_ cord_and_nerve_disorders/multiple_sclerosis_ms_and_related_ disorders/multiple_sclerosis_ms.html? $\mathrm{qt}=\& \mathrm{sc}=\& \mathrm{alt}=$. Accessed April 26, 2012

95. Chan A, Weilbach FX, Toyka KV, Gold R. Mitoxantrone induces cell death in peripheral blood leucocytes of multiple sclerosis patients. Clin Exp Immunol. 2005;139(1):152-158.

96. Fauci AS, Wolff SM, Johnson JS. Effect of cyclophosphamide upon the immune response in Wegener's granulomatosis. N Engl J Med. 1971;285(27):1493-1496.

97. Moreno B, Fernandez-Diez B, Di Penta A, Villoslada P. Preclinical studies of methylthioadenosine for the treatment of multiple sclerosis. Mult Scler. 2010;16(9):1102-1108.

98. Muramatsu T. Midkine: a promising molecule for drug development to treat diseases of the central nervous system. Curr Pharm Des. 2011;17(5):410-423.

99. Dasgupta S, Zhou Y, Jana M, Banik NL, Paha K. Sodium phenylacetate inhibits adoptive transfer of experimental allergic encephalomyelitis in SJL/J mice at multiple steps. J Immunol. 2003;170(7):3874-3882

100. Faraco G, Cavone L, Chiarugi A. The therapeutic potential of HDAC inhibitors in the treatment of multiple sclerosis. Mol Med. 2011;17(5-6):442-447.

101. Zhao X, Kan Q, Zhu L, Zhang GX. Matrine suppresses production of IL-23/IL-17 and ameliorates experimental autoimmune encephalomyelitis. Am J Chin Med. 2011;39(5):933-941.

102. Lutterotti A, Berger T. Advances in multiple sclerosis therapy: new oral disease-modifying agents, CML. Mult Scler. 2010;2:1-10.

103. Yang JS, Xu LY, Xiao BG, Hedlund G, Link H. Laquinimod (ABR-215062) suppresses the development of experimental autoimmune encephalomyelitis, modulates the Th1/Th2 balance and induces the Th3 cytokine TGF-beta in Lewis rats. J Neuroimmunol. 2004;156(1-2):3-9.

104. Warnke C, Meyer HG, Hartung HP, Stuve O, Kieseier BC. Review of teriflunomide and its potential in the treatment of multiple sclerosis. Neuropsychiatr Dis Treat. 2009;5:333-340.

105. Espejo C, Montalba X. Dalfampridine in multiple sclerosis: from symptomatic treatment to immunomodulation. Clin Immunol. 2011;142(1):84-92.

106. Osborne R. Buzz around Campath proof-of-concept trial in MS. Nat Biotechnol. 2009;27(1):6-8.

107. Taupin P. Antibodies against CD20 (rituximab) for treating multiple sclerosis: US20100233121. Expert Opin Ther Pat. 2011;21(1):111-114.

108. Polman CH, O'Connor PW, Havrdova E, Hutchinson M, Kappos L, Miller DH. A randomized, placebo-controlled trial of natalizumab for relapsing multiple sclerosis. $N$ Engl J Med. 2006;354(9): 899-910.

109. Marmont AM. New horizons in the treatment of autoimmune diseases: immunoablation and stem cell transplantation. Annu Rev Med. 2000;51:115-134.

110. Kanwar JR, Sun X, Punj V, et al. Nanoparticles in the treatment and diagnosis of neurological disorders: untamed dragon with fire power to heal. Nanomedicine. 2012;8(4):399-414.
111. McKinney PA. Brain tumours: incidence, survival, and aetiology. J Neurol Neurosurg Psychiatry. 2004;75:ii12- ii17.

112. Baumann $\mathrm{CK}$, Zumwalt $\mathrm{CB}$. Intracranial neoplasms. An overview. AORN J. 1989;50(2):240-242.

113. Graham CA, Cloughesy TF. Brain tumor treatment: chemotherapy and other new developments. Semin Oncol Nurs. 2004;20(4): 260-272.

114. Central Brain Tumor Registry of the United States. Statistical Report: Primary Brain Tumors in the United States, 1992-1997. Chicago, IL: Central Brain Tumor Registry of the United States; 2000.

115. Nelson DF, Martz KL, Bonner H, et al. Non-Hodgkin's lymphoma of the brain: can high dose, large volume radiation therapy improve survival? Report on a prospective trial by the Radiation Therapy Oncology Group (RTOG): RTOG 8315. Int J Radiat Oncol Biol Phys. 1992;23(1):9-17.

116. DeAngelis LM, Seiferheld W, Schold SC, Fisher B, Schultz CJ. Combination chemotherapy and radiotherapy for primary central nervous system lymphoma: Radiation Therapy Oncology Group Study 93-10. J Clin Oncol. 2002;20(4):4643-4648.

117. Mazzola CA, Pollack IF. Medulloblastoma. Curr Treat Options Neurol. 2003;5(3):189-198.

118. Galanis E, Buckner J, Schomberg P. Effective chemotherapy for advanced CNS embryonal tumors in adults. J Clin Oncol. 1997;15(8):2939-2944.

119. Posner JB, Chernik NL. Intracranial metastases from systemic cancer. Adv Neurol. 1978;19:579-592.

120. Mischel PS, Cloughesy TF. Targeted molecular therapy of GBM. Brain Pathol. 2003;13(1):52-61.

121. Tremonts-Lukats IW, Gilbert MR. Advances in molecular therapies in patients with brain tumors. Cancer Control. 2003;10(2): 125-137.

122. Juillerat-Jeanneret $\mathrm{L}$. The targeted delivery of cancer drugs across the blood-brain barrier: chemical modifications of drugs or drugnanoparticles? Drug Discov Today. 2008;13(23-24):1099-1106.

123. Pardridge WM. Blood-brain barrier drug targeting: the future of brain drug development. Mol Interv. 2003;3(2):90-105.

124. Mizuno N, Niwa T, Yotsumoto Y, Sugiyama Y. Impact of drug transporter studies on drug discovery and development. Pharmacol Rev. 2003;55(3):425-461.

125. Egleton RD, Davis TP. Development of neuropeptide drugs that cross the blood-brain barrier. Neuro Rx. 2005;2(1):44-53.

126. Pardridge WM. Molecular Trojan horses for blood-brain barrier drug delivery. Curr Opin Pharmacol. 2006;6(5):494-500.

127. Niidome T, Yamagata M, Okamoto Y, et al. PEG-modified gold nanorods with a stealth character for in vivo applications. J Control Release. 2006;114:343-347.

128. De Jong WH, Borm PJ. Drug delivery and nanoparticles: applications and hazards. Int J Nanomedicine. 2008;3(2):133-149.

129. Lockman PR, Mumper RJ, Khan MA, Allen DD. Nanoparticle technology for drug delivery across the blood-brain barrier. Drug Dev Ind Pharm. 2002;28(1):1-13.

130. Rapoport SI, Ohno K, Fredericks WR, Pettigrew KD. Regional cerebrovascular permeability to [14C] sucrose after osmotic opening of the blood-brain barrier. Brain Res. 1978;150(3):653-657.

131. Phillips MA, Gran ML, Peppas NA. Targeted nanodelivery of drugs and diagnostics. Nano Today. 2010;5(2):143-159.

132. Pardridge WM. Receptor-mediated peptide transport through the blood-brain barrier. Endocr Rev. 1986;7(3):314-330.

133. Pardridge WM, Kang YS, Buciak JL, Yang J. Human insulin receptor monoclonal antibody undergoes high affinity binding to human brain capillaries in vitro and rapid trans-cytosis through the blood-brain barrier in vivo in the primate. Pharm Res. 1995;12(6):807-816.

134. Friden PM. Alkermes Inc, assignee. Transferrin receptor specific antibody-neuropharmaceutical or diagnostic agent conjugates. United States Patent US5833988. November 10, 1998.

135. Pardridge WM, Wu D, Sakane T. Combined use of carboxyldirected protein pegylation and vector-mediated blood-brain barrier drug delivery system optimizes brain uptake of brain-derived neurotrophic factor following intravenous administration. Pharm Res. 1998;15(4):576-582. 
136. Starr CM, Zankel T, Gabathuler R. Biomarin Pharmaceutical Inc, assignee. Delivery of therapeutic compounds to the brain and other tissues. CA2525236. January 13, 2005.

137. Wu D, Yang J, Pardridge WM. Drug targeting of a peptide radio pharmaceutical through the primate blood-brain barrier in vivo with a monoclonal antibody to the human insulin receptor. J Clin Invest. 1997;100(7):1804-1812.

138. Forni F, Vandelli MA, Constantino L. Universita' Degli Studi Di Modena Reggio Emilia E, assignee. Drug delivery peptides for crossing blood-brain barrier. European Patent application EP20050817909. August 22, 2007.

139. Roberts MJ, Bentley MD, Harris JM. Chemistry for peptide and protein PEGylation. Adv Drug Deliv Rev. 2002;54(4):459-476.

140. $\mathrm{Hu} \mathrm{K}$, Li J, Shen Y, et al. Lactoferrin-conjugated PEG-PLA nanoparticles with improved brain delivery: in vitro and in vivo evaluations. J Control Release. 2009;134(1):55-61.

141. Kreuter J. Nanoparticulate systems for brain delivery of drugs. $A d v$ Drug Deliv Rev. 2001;47(1):65-81.

142. Steiniger SC, Kreuter J, Khalansky AS, et al. Chemotherapy of glioblastoma in rats using doxorubicin-loaded nanoparticles. Int $J$ Cancer. 2004;109(5):759-767.

143. Wang CX, Huang LS, Hou LB, et al. Antitumor effects of polysorbate- 80 coated gemcitabine polybutylcyanoacrylate nanoparticles in vitro and its pharmacodynamics in vivo on C6 glioma cells of a brain tumor model. Brain Res. 2009;1261:91-99.

144. Petri B, Bootz A, Khalansky A, et al. Chemotherapy of brain tumor using doxorubicin bound to surfactant-coated poly(butyl cyanoacrylate) nanoparticles: revisiting the role of surfactants. J Control Release. 2007;117(1):51-58.

145. Gelperina S, Maksimenko O, Khalansky A, et al. Drug delivery to the brain using surfactant-coated poly(lactide-co-glycolide) nanoparticles: influence of the formulation parameters. Eur J Pharm Biopharm. 2010;74(2):157-163.

146. Kulkarni SA, Feng SS. Effects of surface modification on delivery efficiency of biodegradable nanoparticles across the blood-brain barrier. Nanomedicine. 2011;6(2):377-394.

147. Pandey R, Sharma A, Zahoor A, Sharma S, Khuller GK. Poly(dllactide-co-glycolide) nanoparticles based inhalable sustained drug delivery system for experimental tuberculosis. J Antimicrob Chemother. 2003;52(6):981-986.

148. Gan CW, Feng SS. Transferrin-conjugated nanoparticles of poly(lactide)-D- $\alpha$-tocopheryl polyethylene glycol succinate diblock copolymer for targeted drug delivery across the blood-brain barrier. Biomaterials. 2010;31(30):7748-7757.

149. Carroll RT, Bhatia D, Geldenhuys W, et al. Brain-targeted delivery of Tempol-loaded nanoparticles for neurological disorders. J Drug Target. 2010;18(9):665-674.

150. Huang R, Ke W, Han L, Liu Y, Shao K, Jiang C. Lactoferrin-modified nanoparticles could mediate efficient gene delivery to the brain in vivo. Brain Res Bull. 2010;81(6):600-604.

151. Agyare EK, Curran GL, Ramakrishnan M, Yu CC, Poduslo JF, Kandimalla KK. Development of a smart nano-vehicle to target cerebrovascular amyloid deposits and brain parenchymal plaques observed in Alzheimer's disease and cerebral amyloid angiopathy. Pharm Res. 2008;25(11):2674-2684.

152. Wang ZH, Wang ZY, Sun CS, Wang CY, Jiang TY, Wang SL. Trimethylated chitosan-conjugated PLGA nanoparticles for the delivery of drugs to the brain. Biomaterials. 2010;31(5): 908-915.

153. Neely A, Perry C, Varisli B, et al. Ultrasensitive and highly selective detection of Alzheimer's disease biomarker using twophoton Rayleigh scattering properties of gold nanoparticle. ACS Nano. 2009;3(9):2834-2840.
154. Huang S, Li J, Han L, et al. Dual targeting effect of Angiopep-2-modified, DNA-loaded nanoparticles for glcoma. Biomaterials. 2011;32(38):6832-6838.

155. Huang R, Ke W, Han L, Li J, Liu S, Jiang C. Targeted delivery of chlorotoxin-modified DNA-loaded nanoparticles to glioma via intravenous administration. Biomaterials. 2011;32(9):2399-2406.

156. Huile G, Shuaiqi P, Zhi Y, et al. A cascade targeting strategy for brain neuroglial cells employing nanoparticles modified with angiopep-2 peptide and EGFP-EGF1 protein. Biomaterials. 2011;32(33):8669-8675.

157. Tian XH, Lin XN, Wei F, et al. Enhanced brain targeting of temozolomide in polysorbate- 80 coated polybutylcyanoacrylate nanoparticles. Int J Nanomedicine. 2011;6:445-452.

158. Guo J, Gao X, Su L, et al. Aptamer-functionalized PEG-PLGA nanoparticles for enhanced anti-glioma drug delivery. Biomaterials. 2011;32(31):8010-8020.

159. Fillmore HL, Shultz MD, Henderson SC, et al. Conjugation of functionalized gadolinium metallofullerenes with IL-13 peptides for targeting and imaging glial tumors. Nanomedicine (Lond). 2011;6(3):449-458.

160. Li J, Feng L, Fan L, et al. Targeting the brain with PEG-PLGA nanoparticles modified with phage-displayed peptides. Biomaterials. 2011;32(21):4943-4950.

161. Park J, Gao W, Whiston R, Strom TB, Metcalfe S, Fahmy TM. Modulation of CD4+ T lymphocyte lineage outcomes with targeted, nanoparticle-mediated cytokine delivery. Mol Pharm. 2011;8(1): $143-152$

162. Van Kasteren SI, Campbell SJ, Serres S, Anthony DC, Sibson NR, Davis BG. Glyconanoparticles allow pre-symptomatic in vivo imaging of brain disease. Proc Natl Acad Sci U S A. 2009;106(1):18-23.

163. Yurko Y, Maximov V, Andreozzi E, Thompson GL, Vertegel AA. Design of biomedical nanodevices for dissolution of blood clots. Mater Sci Eng C Mater Biol Appl. 2009;29(3):737-741.

164. Marsh JN, Hu G, Scott MJ, et al. A fibrin-specific thrombolytic nanomedicine approach to acute ischemic stroke. Nanomedicine (Lond). 2011;6(4):605-615.

165. Baratchi S, Kanwar RK, Kanwar JR. Survivin mutant protects differentiated dopaminergic SK-N-SH cells against oxidative stress. PLoS One. 2011;6(1):e15865.

166. Baratchi S, Kanwar RK, Antonio Cheung CH, Kanwar JR. Proliferative and protective effects of SurR9-C84A on differentiated neural cells. J Neuroimmunol. 2010;227(1-2):120-132.

167. Wynne A, Kanwar RK, Khanna R, Kanwar JR. Recent advances on the possible neuroprotective activities of Epstein-Barr virus oncogene BARF1 protein in chronic inflammatory disorders of central nervous system. Curr Neuropharmacol. 2010;8(3):268-275.

168. Kanwar JR, Kanwar RK, Krissansen GW. Simultaneous neuroprotection and blockade of inflammation reverses autoimmune encephalomyelitis. Brain. 2004;127(Pt 6):1313-1331.

169. Kanwar JR, Kanwar RK, Wang D, Krissansen GW. Prevention of a chronic progressive form of experimental autoimmune encephalomyelitis by an antibody against mucosal addressin cell adhesion molecule-1, given early in the course of disease progression. Immunol Cell Biol. 2000;78(6):641-645.

170. Kanwar JR, Harrison JEB, Wang D, et al. b7 integrins contribute to demyelinating disease of the central nervous system. J Neuroimmunol. 2000;103(2):146-152.

171. Wengel J. Synthesis of $3^{\prime}$-C- and 4'-C- branched oligonucleotides and the development of locked nucleic acid (LNA). Acc Chem Res. 1999;32:301-310. 


\section{Publish your work in this journal}

The International Journal of Nanomedicine is an international, peerreviewed journal focusing on the application of nanotechnology in diagnostics, therapeutics, and drug delivery systems throughout the biomedical field. This journal is indexed on PubMed Central, MedLine, CAS, SciSearch $\AA$, Current Contents ${ }^{\circledR} /$ Clinical Medicine,

Journal Citation Reports/Science Edition, EMBase, Scopus and the Elsevier Bibliographic databases. The manuscript management system is completely online and includes a very quick and fair peer-review system, which is all easy to use. Visit http://www.dovepress.com/ testimonials.php to read real quotes from published authors.

Submit your manuscript here: http://www.dovepress.com/international-journal-of-nanomedicine-journal 